\title{
Enzymatic synthesis of bioactive compounds with high potential for cosmeceutical application
}

\author{
Io Antonopoulou $^{1} \cdot$ Simona Varriale $^{2}$ • Evangelos Topakas ${ }^{3}$ - Ulrika Rova ${ }^{1}$. \\ Paul Christakopoulos ${ }^{1} \cdot$ Vincenza Faraco $^{2}$
}

Received: 19 April 2016/Revised: 22 May 2016/Accepted: 24 May 2016/Published online: 8 June 2016

(C) The Author(s) 2016. This article is published with open access at Springerlink.com

\begin{abstract}
Cosmeceuticals are cosmetic products containing biologically active ingredients purporting to offer a pharmaceutical therapeutic benefit. The active ingredients can be extracted and purified from natural sources (botanicals, herbal extracts, or animals) but can also be obtained biotechnologically by fermentation and cell cultures or by enzymatic synthesis and modification of natural compounds. A cosmeceutical ingredient should possess an attractive property such as anti-oxidant, anti-inflammatory, skin whitening, anti-aging, anti-wrinkling, or photoprotective activity, among others. During the past years, there has been an increased interest on the enzymatic synthesis of bioactive esters and glycosides based on (trans)esterification, (trans)glycosylation, or oxidation reactions. Natural bioactive compounds with exceptional theurapeutic properties and low toxicity may offer a new insight into the design and development of potent and beneficial cosmetics. This review gives an overview of the enzymatic modifications which are performed currently for the synthesis of products with attractive properties for the cosmeceutical industry.
\end{abstract}

Keywords Lipases · Feruloyl esterases - Tannases · Transferases · Glycosidases · Proteases $\cdot$ Laccases · Anti-oxidant $\cdot$ Anti-microbial $\cdot$ Anti-inflammatory $\cdot$ Skin

Vincenza Faraco

vfaraco@unina.it

1 Division of Chemical Engineering, Department of Civil, Environmental and Natural Resources Engineering, Luleå University of Technology, 97187 Luleå, Sweden

2 Department of Chemical Sciences, University of Naples "Federico II”, Naples, Italy

3 Biotechnology Laboratory, School of Chemical Engineering, National Technical University of Athens, 15700 Athens, Greece whitening $\cdot$ Anti-wrinkling $\cdot$ Anti-aging $\cdot$ Photoprotective . Fungal $\cdot$ Bacterial

\section{Introduction}

Articles defined as cosmetics are intended for human body application aiming at increased beauty and attraction or cleaning use, without affecting the body structure or function (Nelson and Rumsfield 1988). During the last few years, the cosmetic industry is searching for bioactive compounds that also promote health benefits. This combination resulted in a new term called "cosmeceutical" where cosmetic products assert medical benefits (Choi and Berson 2006). Cosmeceuticals are different from cosmetics and drugs, as they affect the function and structure of skin, while having drug-like effects that are marketed using skin appearancebased claims. Cosmeceutical industry numbers over 400 manufacturers worldwide including Estée Lauder, L'Oréal, Procter $\&$ Gamble, and Avon, with $80 \%$ of the US and European market dedicated to skin care (Brandt et al. 2011). In 2008, Japan was by far the biggest market in cosmeceuticals valued at $\$ 6-8$ billion, followed by the USA ( $\$ 5-6$ billion) and EU (\$3-5 billion) (Kim and Wijesekara 2012). Market growth is expected to rise in economies like China, Brazil, the Russian Federation, and India (Brandt et al. 2011). Nevertheless, the Food and Drug Administration (FDA) does not recognize cosmeceutical as a term even if it is widely used in industry, while in the EU, most are considered as cosmetics (Sharma 2011). There is no regulation of cosmeceuticals in EU, the USA, and Japan; however, as the interaction between cosmetic and skin is complex, there is an increased attention towards the need of toxicological tests of the final product and its bioactive ingredients (Nohynek et al. 2010). Target ingredients of cosmeceuticals may include phytochemicals, 
vitamins, peptides, enzymes, essential oils among others, which are incorporated into lotions, creams, and ointments dedicated to skin treatment. Desired properties, such as anti-oxidant, antiaging, anti-microbial, anti-wrinkling, photoprotective, or skin whitening, are preferentially offered by natural compounds derived from plant or sea organisms, instead of chemically synthetic compounds. The guidelines of the Council of Europe define a natural cosmetic as a product that consists of natural substances of botanical, mineral, or animal origin, exclusively obtained through physical, microbiological, or enzymatic methods, with certain exceptions for fragrances and preservatives. This demand has increased the sales of personal care products based on natural ingredients; however, often a modification of the bioactive compounds is required prior to their application in the final product, e.g., by increasing its lipophilicity or improving its biological properties. Modification with fatty compounds generally results in more lipophilic products, whereas modification with sugars results in more hydrophilic derivatives. Chemical approaches have numerous disadvantages such as the protection and deprotection of groups resulting in many reaction steps, use of strong acid as catalyst, high temperatures $\left(150-200{ }^{\circ} \mathrm{C}\right)$, formation of unwanted products, dark color, burnt taste of product, and high energy consumption (Kiran and Divakar 2001). Enzymatic modification is employed under mild conditions, is highly selective, and includes one single step.

In this review, the most important enzymatic modifications that result to the synthesis of ingredients with attractive

\section{Esterification (reverse hydrolysis):}

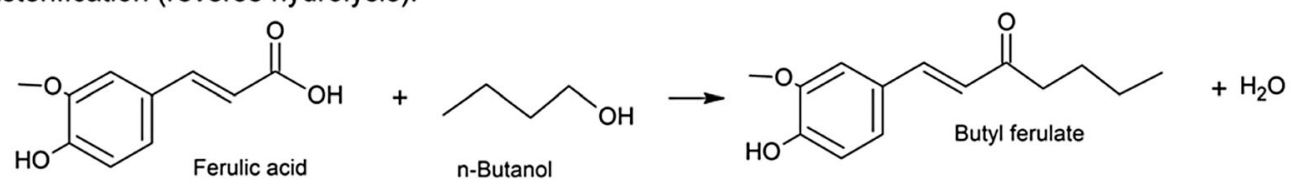

Transesterification

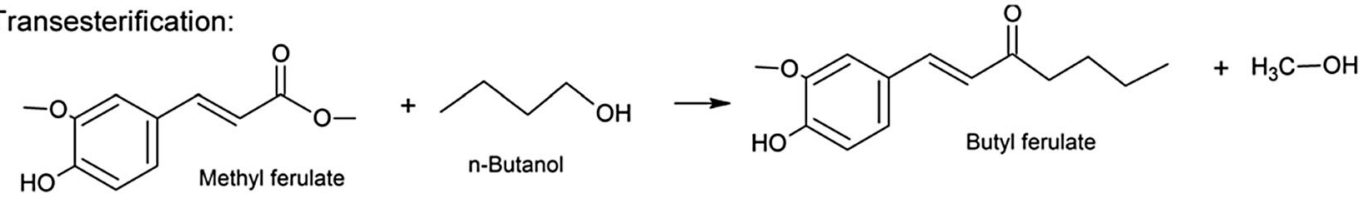

Glycosylation (reverse hydrolysis):

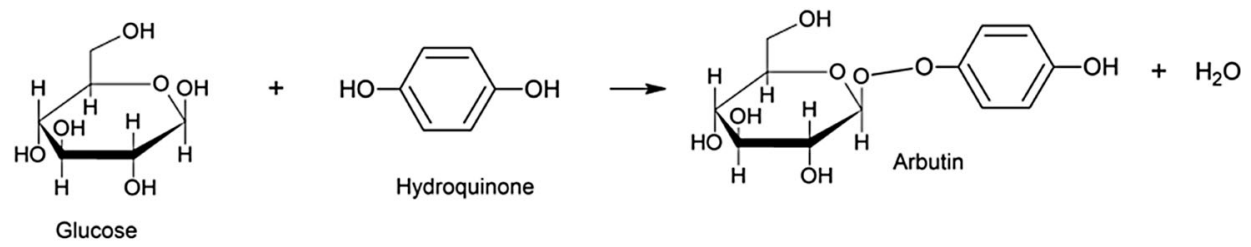

Transglycosylation:
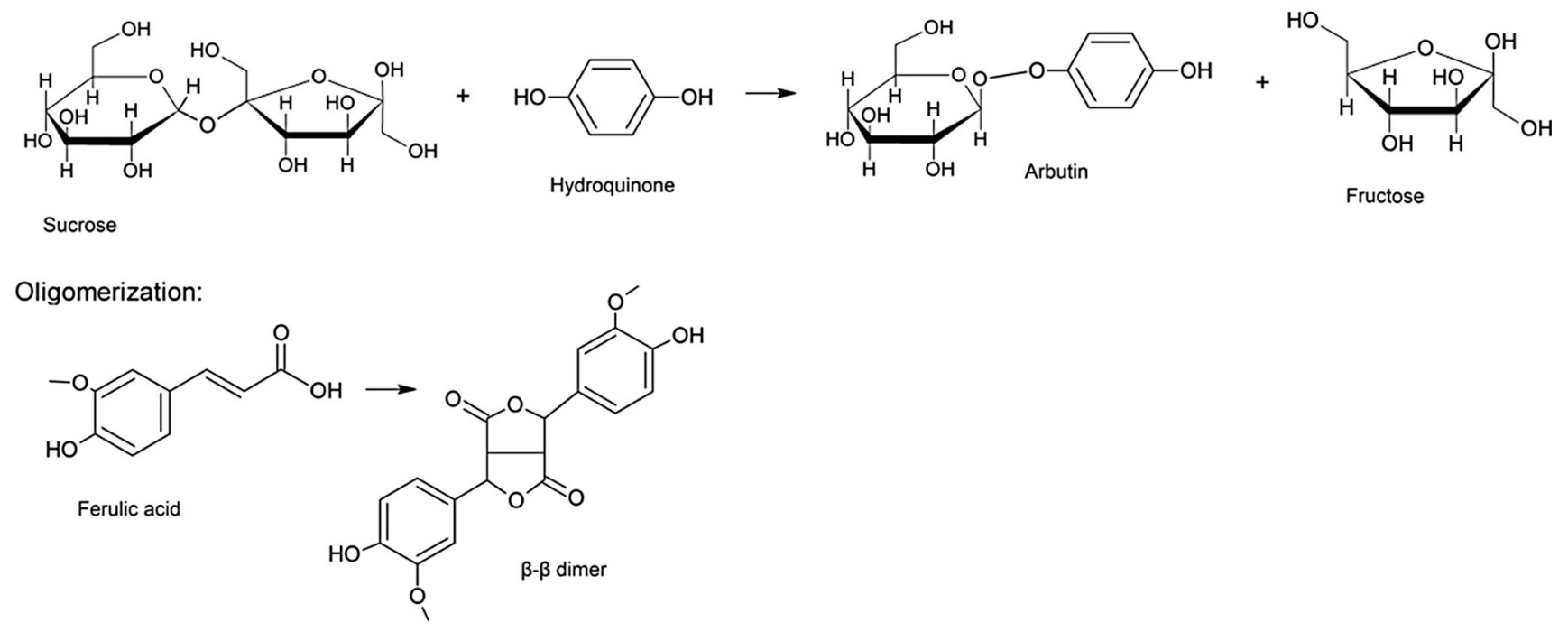

Fig. 1 Reaction examples 
properties for the cosmeceutical industry are documented. Properties such as anti-oxidant, anti-inflammatory, anti-microbial, skin-whitening, and photoprotective effects were criteria for the selection of the reported modification reactions. A modification may follow different mechanisms: direct esterification or transesterification performed by esterases (such as lipases, feruloyl esterases, or tannases) and proteases, glycosylation (reverse hydrolysis) or transglycosylation performed by transferases, and $\beta$-glucosidases and oligomerization performed by laccases. Examples of such modification reactions are presented in Fig. 1.

\section{Esterases}

Except for their hydrolytic ability, esterases are able to perform (trans)esterification reactions. Triaglycerol lipases (EC 3.1.1.3) are most commonly used due to their broad specificity, as shown in Table 1. Less popular, ferulic acid esterases (FAEs; EC 3.1.1.73) generally catalyze the hydrolysis of the ester bond between the main chain polysaccharides of xylans or pectins and the monomeric or dimeric ferulic acid in plants; however, they are able to modify hydroxycinnamic acids and their esters. Tannases (tannin acyl hydrolases, EC 3.1.1.20) are known to be active on complex polyphenolics, catalyzing the hydrolysis or synthesis of the "ester bond" (galloyl ester of an alcohol moiety) or the "depside" bond (galloyl ester of gallic acid) (Battestin et al. 2008). Low water content is essential for the thermodynamic shift of equilibrium towards synthesis. Different systems have been employed including organic co-solvents, ionic liquids, solvent-free systems, supercritical fluids, and molecular sieves as water removal agents. The ideal solvent should aid solubilization of substrates, not affect enzyme activity, have low toxicity, and enable easy product recovery (Wei et al. 2002). Ionic liquids are a good alternative since they generally do not deactivate esterases and have exceptional tailorability and low volatility (Zeuner et al. 2011). However, a number of issues including the cost involved in large-scale usage are to be addressed. Aids as microwave irradiation and ultrasound treatment have been employed in lipase-catalyzed reactions (Costa et al. 2014; Cui et al. 2013). Detergentless microemulsions, so far employed in FAE-catalyzed reactions, consist of a hydrocarbon, a short-chained alcohol, and water representing thermodynamically stable dispersions of aqueous microdroplets in the hydrocarbon solvent (Khmelnitsky et al. 1988). An important advantage of these mixtures is the separation of reaction products and enzyme reuse, while the solubility of relatively polar phenolic acids is high owing to the presence of large amount of polar alcohol.

\section{$\alpha$-Hydroxy acid derivatives}

$\alpha$-Hydroxy acids (AHAs) are composed of carbon backbones containing a carboxyl group and a hydroxyl group on the adjacent carbon. Among them, glycolic acid, lactic acid, and malic acid have been well known in cosmetics as beauty aids and peeling agents due to their hygroscopic, emulsifying, and exfoliating properties (Tung et al. 2000). Short-chain AHAs as lactic acid are more active in regulating the rate of skin regeneration and improving dryness (Wei et al. 2002). However, limiting factors for application are their acidicity and the rapid penetration into the deep epiderm, causing irritant effects at concentrations $>10 \%$. To control their concentration and penetration to the skin's intercellular spaces, AHAs have been grafted onto alkylglycosides, fatty acids, or fatty alcohols so they can be gradually released by the epidermis esterases. Short-chain alkylglycosides have been reported to relieve the irritant effects on skin after UV radiation (Wei et al. 2003). A major concern regarding enzymatic modification is that lactic acid can undergo self-polymerization at high temperatures and low water content forming linear polyesters or lactones because of the presence of groups that act as acyl donor and nucleophile at the same time (Roenne et al. 2005). A key factor is the choice of enzyme that favors the desired reaction. Lactic acid does not act as nucleophile when the lipase B from Candida antarctica (CALB) is used as biocatalyst due to steric hindrance at the enzyme's active site (Form et al. 1997). Another obstacle is the severe inactivation of enzymes in high concentrations of lactic acid or in solvent-free systems, as it decreases the $\log \mathrm{P}$ of the reaction medium (Pirozzi and Greco 2004). Polar solvents aid lactic acid solubilization at higher concentrations and seem to prevent enzyme inactivation because they show an acid-suppressive effect due to their basicity (Hasegawa et al. 2008). However, esterification of glycolic acid has been favored in apolar hexane producing high yield of glycolate ester (91\% after $24 \mathrm{~h}$ ) (Torres and Otero 1999). Limitation of lactic acid self-polymerization has been achieved in hexane although the esterification with fatty acids resulted in lower yields (35\%) (Torres and Otero 2001). Transesterification between $\alpha$-butyl glycoside and butyl lactate in a solvent-free system eliminating the butanol coproduct under reduced pressure resulted in more than $95 \%$ conversion and very high concentration of a less irritant product $(170 \mathrm{~g} / \mathrm{L})$ in a single batch reaction (Bousquet et al. 1999).

\section{Kojic acid derivatives}

Kojic acid (5-hydroxy-2-(hydroxymethyl)-4H-pyran-4-one) is an inexpensive water-soluble fungal secondary metabolite produced by Aspergillus and Penicillium species. It possesses valuable biological properties such as anti-oxidant, anti-microbial, and anti-inflammatory, while as an iron and copper chelator has the capacity to prevent photodamage, 


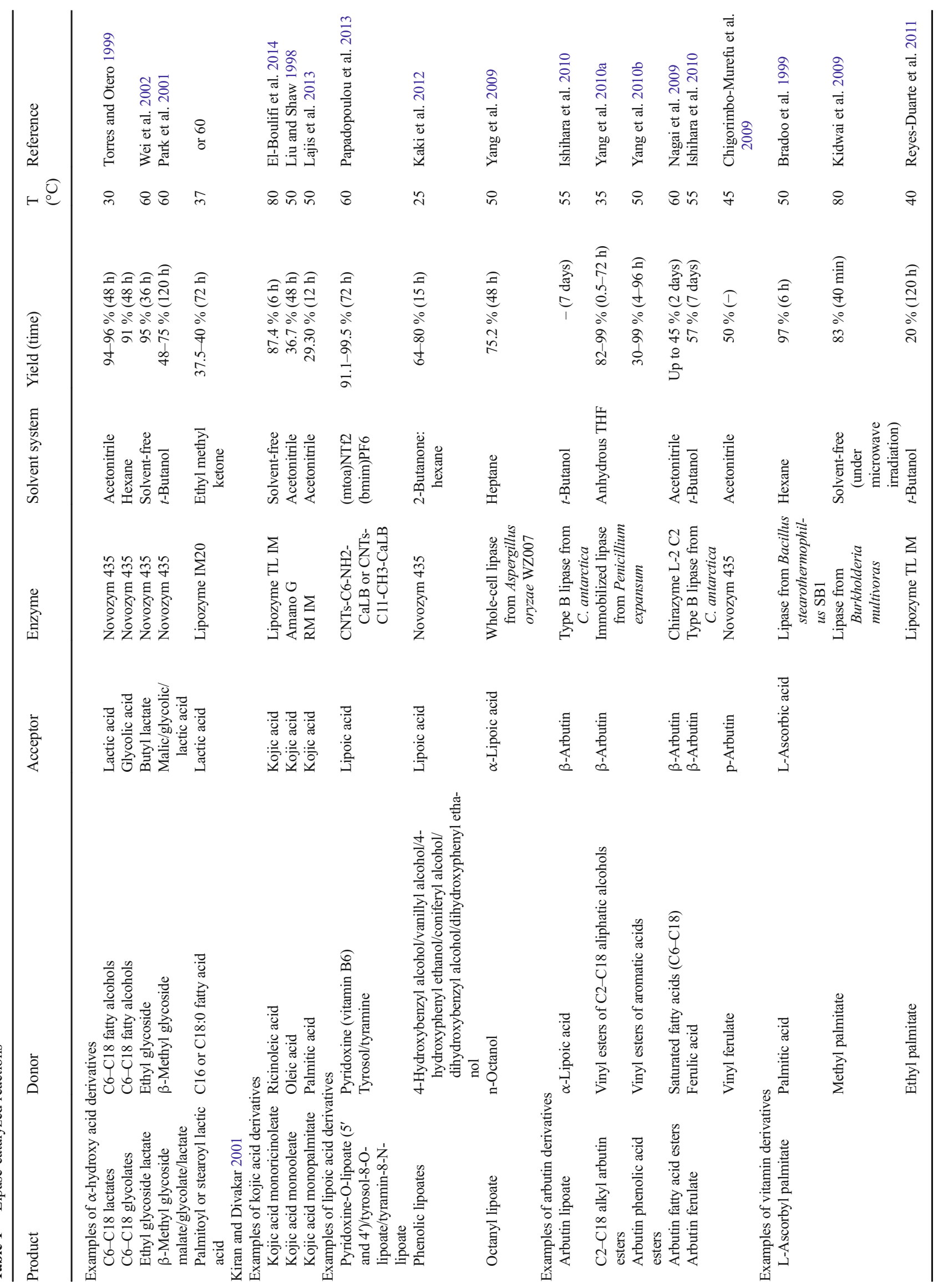




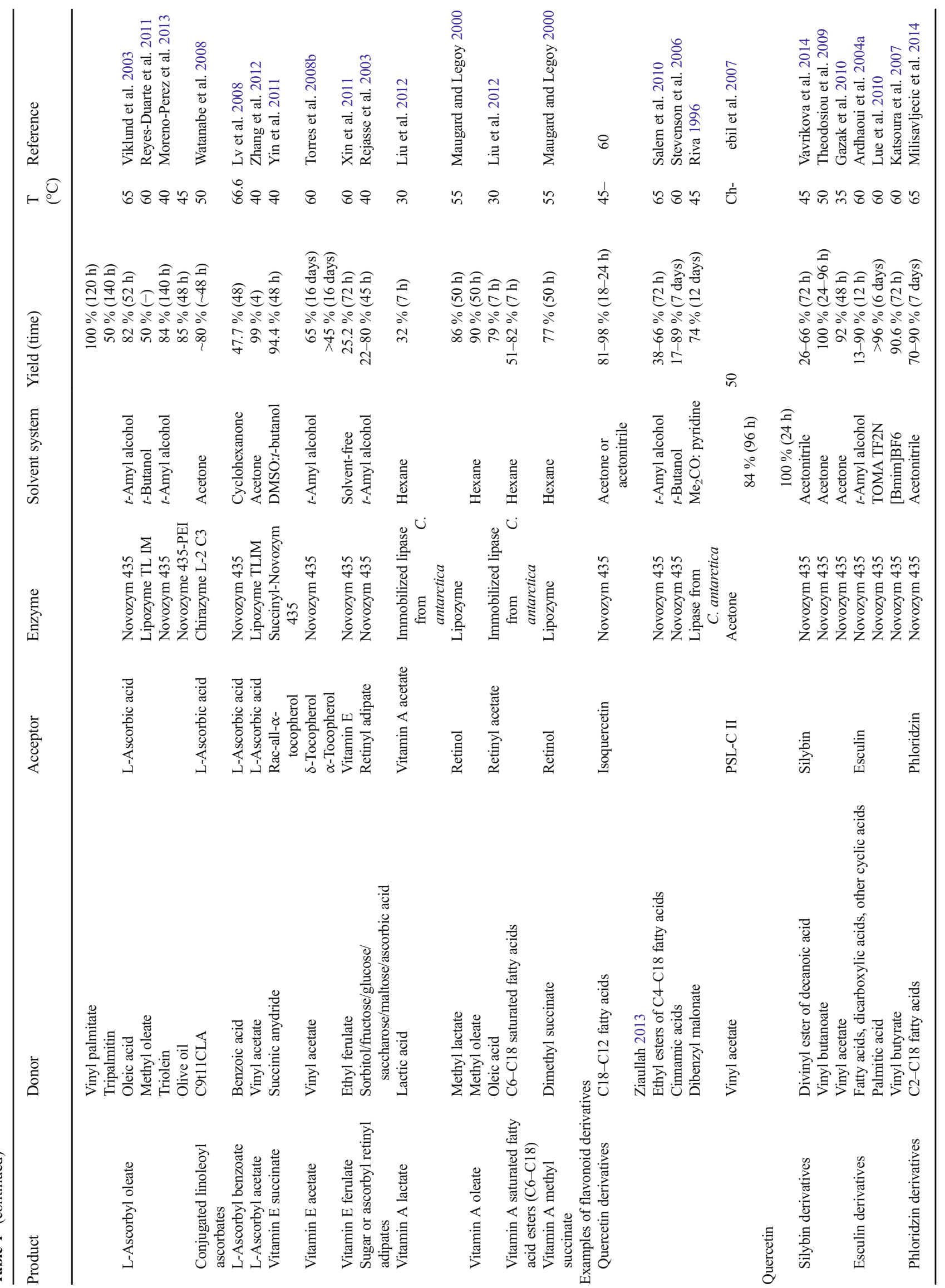




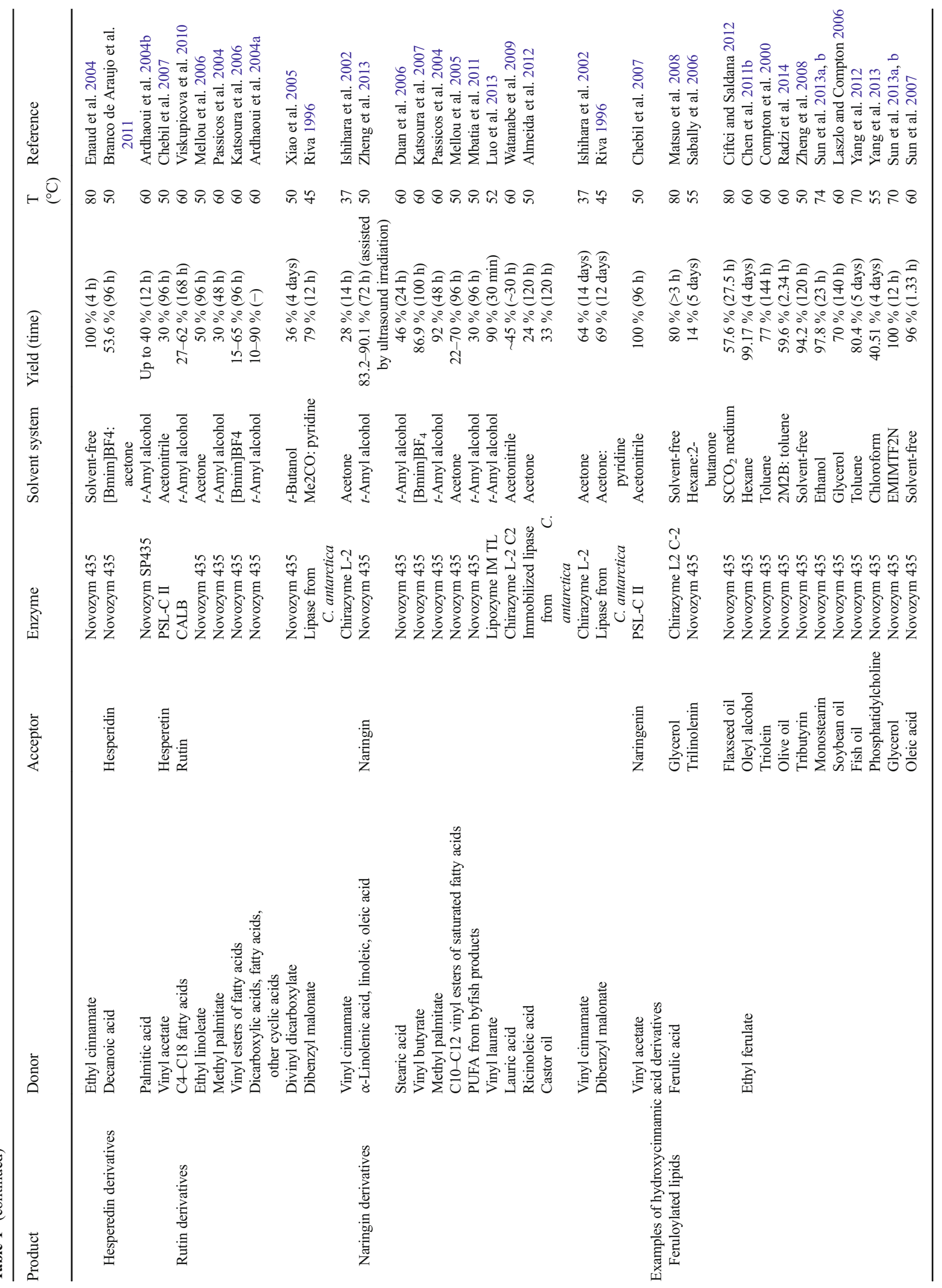




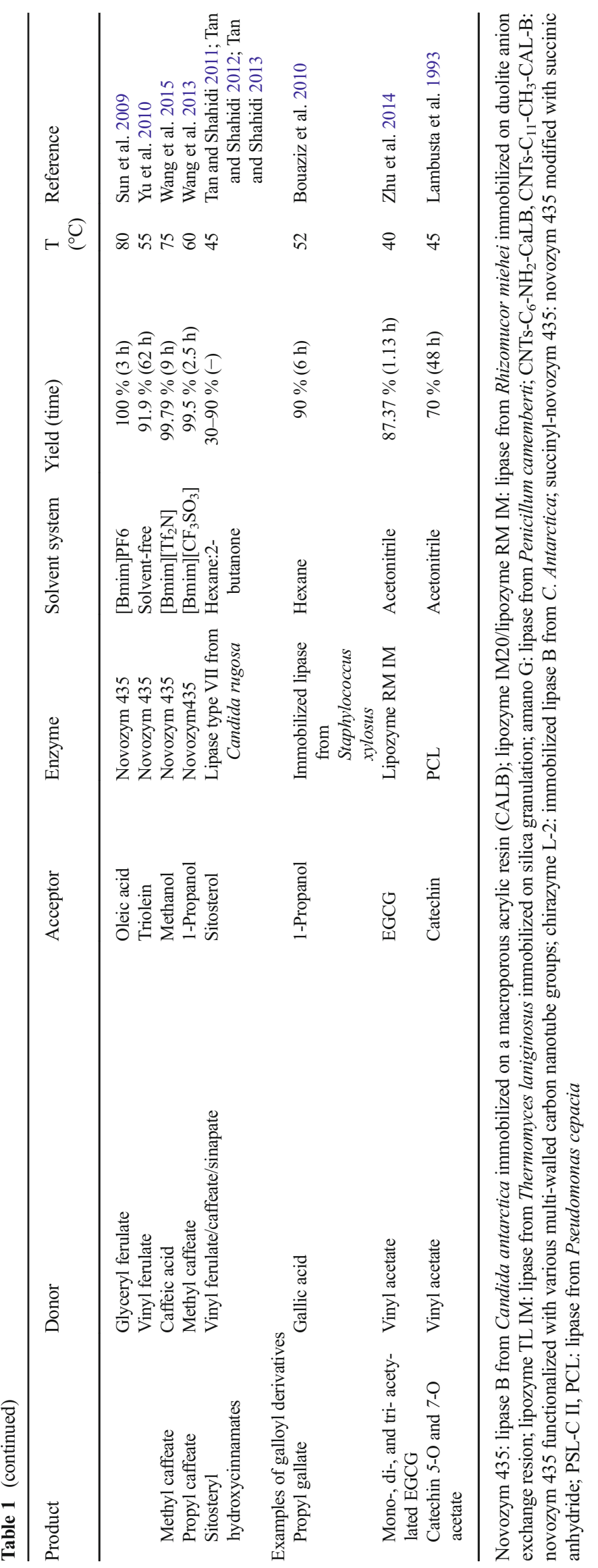


hyperpigmentation, and skin wrinkling. Its primary use in cosmetics is as a skin whitening agent but there are concerns regarding its skin compatibility, oil solubility, and storage stability even at ordinary temperatures. Additionally, there is evidence of toxicity, irritancy, and carcinogenicity (Lajis et al. 2012). The first attempts on the enzymatic modification of kojic acid focused on the synthesis of kojic acid glycosides using a sucrose phosphorylase from Leuconostoc mesenteroides, an $\alpha$-amylase from Bacillus subtilis and an immobilized $\beta$-galactosidase from Bacillus circulans (Nishimura et al. 1994; Kitao and Serine 1994; Hassan et al. 1995). However, many lipophilic derivatives such as saturated fatty (C6-C18) acid esters and the unsaturated kojic acid monoricinolate and monooleate have been synthesized by commercial lipases (Liu and Shaw 1998; Lajis et al. 2013; Khamaruddin et al. 2008; El-Boulifi et al. 2014; Ashari et al. 2009). A phospholipase from Streptomyces sp. has synthesized phosphatidylkojic acid at $60 \%$ yield from a dipalmitoylphosphatidyl residue (Takami et al. 1994). Kojic acid has two $\mathrm{OH}-$ groups, the primary at $\mathrm{C}-7$ and the secondary one at $\mathrm{C}-5$ which is essential to the radical scavenging and tyrosinase interference activity. Many derivatives have been synthesized by modifying the $5-\mathrm{OH}$ group; nevertheless, CALB showed moderate yield (53\%) synthesizing a laurate product esterified at the primary C-7 (Kobayashi et al. 2001; Chen et al. 2002).

\section{Lipoic acid derivatives}

$\alpha$-Lipoic acid is a dithiol compound containing two sulfur atoms at the C-6 and C-8 carbons connected by a disulfide bond. It takes part in the anti-oxidant defense system of the cell through its ability to scavenge free radicals both in lipid and aqueous environments. This amphiphilicity constitutes it an ideal candidate for use in both oil- and water-based formulations. Moreover, it participates in the regeneration of antioxidants (i.e., vitamic C, vitamin $\mathrm{E}$ ) and in the de novo synthesis of endogenous anti-oxidants (i.e., glutathione) and shows metal ion chelating activity, while it can repair oxidative damage in macromolecules (Papadopoulou et al. 2013). Other attractive properties include anti-inflammatory activity, aid in the treatment of diseases such as diabetes, atherosclerosis, cardiovascular, heavy-metal poisoning, radiation damage, cancer, Alzheimer's, and AIDS (Maczurek et al. 2008). Synthesis of lipoic acid phenolic derivatives by CALB showed that a prior aromatic hydroxylation of the donor offered higher 2,2-diphenyl-1-picrylhydrazyl (DPPH) radical scavenging activity to the products. The hydroxytyrosol ester of lipoic acid showed similar anti-oxidant activity to $\alpha$ tocopherol but higher than the commercial butylated hydroxytoluene (BHT) (Kaki et al. 2012). Lipoic acid is found in a racemic mixture, where the (R)-enantiomer is much more active than the (S)-enantiomer. Only lipases from Candida rugosa and Aspergillus oryzae (whole cell) have been reported to enable kinetic resolution of racemic $\alpha$-lipoic acid (Yan et al. 2009; Fadnavis et al. 1998).

\section{Hydroquinone derivatives}

Hydroquinone, a phenolic compound with two-OH groups at the para positions of the benzene ring, has been commercially used in cosmetics at concentrations $<1 \%$ as an anti-oxidant, fragrance, reducing agent, or polymerization inhibitor (Andersen et al. 2010). Its most promising use is as a skin whitening agent; however, it is prone to cause irritations and dermatitis (Kang et al. 2009). Its glycosylated derivative, arbutin, has attracted attention as a better tyrosinase inhibitor when compared to conventional agents as it inhibits melanogenesis without causing melanocytotoxicity (Sugimoto et al. 2005). It also plays an important role in scavenging free radicals, as an anti-inflammatory, and an anti-microbial agent (Lee and Kim 2012). Arbutin has two isomers ( $\alpha$ - and $\beta-$ ). The first is synthesized by chemical or enzymatic methods and shows higher efficiency and stability while the latter is extracted from natural sources such as bearberry, cranberry, blueberry, and pears (Seo et al. 2012a). $\alpha$-Arbutin possesses a 10-fold stronger inhibitory effect on the activity of tyrosinase from human malignant melanoma cells compared to its anomer, whereas $\beta$-arbutin reduces tyrosinase activities from mushroom and mouse melanoma (Seo et al. 2012b). $\alpha$-Arbutin shows extremely increased browning resistance to light irradiation compared to hydroquinone (Kitao and Sekine 1994). Lipases have been used for the acylation of $\beta$-arbutin with aromatic or fatty acids showing absolute regioselectivity at the $6^{\prime}$ position. This phenomenon can be attributed to the hypothesis that the primary $\mathrm{OH}-$ group of the sugar moiety is less hindered so it can enter more easily into the active site of the lipase and attach the acyl-enzyme intermediate. Studies on immobilized lipase from Penicillium expansum showed that the elongation of the donor chain length $(\mathrm{C} 2-\mathrm{C} 8)$ results in higher initial yields perhaps due to stronger interactions with the hydrophobic acyl binding site of the enzyme. Branched-chain acyl donors affect negatively the initial rate due to steric strain while the presence of a conjugated $\mathrm{C}-\mathrm{C}$ double bond adjacent to the carbonyl moiety decreases the rate substantially (Yang et al. 2010a). The radical scavenging activity of acyl (C6-C18) arbutin is independent of the chain length (Nagai et al. 2009). Fatty acid derivatives of arbutin show higher anti-melanogenesis and anti-oxidant activity than arbutin which could be allied to the improved membrane penetration, due to increased lipophilicity (Watanabe et al. 2009). Synthesized by CALB, arbutin ferulate was found to have $19 \%$ higher activity against the 2,2'-azino-bis(3-ethylbenzothiazoline-6-sulphonic acid (ABTS) free radical than ferulic acid and be $10 \%$ more efficient towards low-density lipoprotein (LDL), showing higher anti-oxidant than Trolox, a well- 
known analog of vitamin $\mathrm{E}$ and commercial anti-oxidant (Chigorimbo-Murefu et al. 2009).

\section{Vitamin derivatives}

L-Ascorbic acid (vitamin C) is a potent water-soluble natural anti-oxidant that has been used in cosmetics as a preservative, $\mathrm{pH}$ adjuster, or/and an active compound. It has been proved that ascorbates promote collagen synthesis in human skin fibroblasts in vitro up to eightfold capacity, while they show photoprotective activity against UVA and UVB irradiation and have wound healing properties (Murad et al. 1981). Drawbacks as instability, poor liposolubility, and low skin penetrability have led to modifications. Common saturated fatty acid derivatives, as ascorbyl palmitate and ascorbyl stearate, have been synthesized showing that there is no negative effect on the radical scavenging activity by introducing a saturated group at the C-6 position of ascorbic acid (Watanabe et al. 2003). Enzymatic synthesis of ascorbyl palmitate is focused on the esterification of palmitic acid with a vast use of CALB in organic solvents or ionic liquids. Other commercial lipases have been employed offering varying yields (6-97\%) (Gulati et al. 1999; Costa et al. 2014; Park et al. 2003; Hsieh et al. 2006, Bradoo et al. 1999). However, saturated fatty acid esters still show moderate solubility in oils. Further improvement can be done by introducing a double bond in the fatty acid, resulting in superior products in terms of solubility and radical scavenging capacity. For instance, oleic acid is readily available and inexpensive (Viklund et al. 2003). There are reports on esterification of olive oil, palm oil, or lard offering a simple, direct, and natural route for synthesis (Moreno-Perez et al. 2013; Zhao et al. 2014; Burham et al. 2009). Derivatization of L-ascorbic acid requires mild conditions to prevent oxidation of both acid and its esters and high regioselectivity for the 6-O-position which is achieved by lipases (Zhang et al. 2012). However, the demand of polar solvents for enhancing substrate solubility tends to be deleterious for their stability. Coating is an effective way to protect immobilized lipases from denaturation reducing the interactions with the solvent (Moreno-Perez et al. 2013). The use of vinyl ester donors increases the reaction rate, but implies the release of fatty acids from oils and their further activation. For instance, CALB offered $100 \%$ conversion of vinyl palmitate in $t$-butanol (Reyes-Duarte et al. 2011). When methyl esters are used, the by-product methanol is insoluble in oils, gets adsorbed onto the surface of the immobilized lipase, and leads to negative effects on enzyme activity and operational stability.

Vitamin E is a general term for a group of amphiphilic lipids, comprising of four tocopherols, having a saturated phytyl side chain attached to the chromanol core and four tocotrienols having an attached unsaturated isoprenoid side chain. The analogs differ with each other by the presence and placement of methyl groups around the aromatic ring. In nature, vitamin E occurs only in the $R R R$-form, while $R R R$ - $\alpha$ tocopherol is the most bioactive. Synthetic vitamin E ( $\alpha$ tocopherol) is a racemic mixture of eight stereoisomers in equal amounts (all-rac- $\alpha$ ), of which not all are as bioactive as the natural form (Torres et al. 2008a). Vitamin E is nonirritant to the eyes and skin, has high anti-oxidant activity with anti-aging and anti-tumor potential, inhibits the UVB-induced lipid peroxidation, and shows skin-improving properties with anti-inflammatory and beneficial effect on the skin barrier function (Zondlo Fiume 2002). However, it is readily destabilized by light and oxygen. Non-enantioselective acetylation of vitamin $\mathrm{E}$ at the $\mathrm{C}-6$ carbon has been performed only by CALB among other tested enzymes which can be explained by studies that show that the acceptor binding site is deeper in lipase B (Torres et al. 2008b; Pleiss et al. 1998). $\delta$ Tocopherol gave higher rates due to its lower methylation degree, while competitive acetylation experiments indicated that there is steric hindrance caused by the aliphatic chain and not the chromanol ring. Vitamin E succinate has been synthesized by modified CALB yielding $94 \%$ and by a lipase from C. rugosa with moderate yields (Yin et al. 2011; Jiang et al. 2013). Synthesized at lower yields $(25.2 \%)$ by CALB, novel vitamin $\mathrm{E}$ ferulate inhibits melanogenesis in human melanoma cells, being an attractive candidate as a skin-whitening agent (Xin et al. 2011).

Vitamin A includes a group of unsaturated compounds, i.e., retinol, retinoic acid, and retinaldehyde, which are widely used in cosmetic and skin care products because of their anti-oxidant, anti-aging, and skin-whitening properties. Retinol is the most active form of vitamin A; however, retinoids are readily oxidized in air and inactivated by UV light while they are water-insoluble and skin-irritating (Maugard and Legoy 2000). The most common modification of retinol is retinyl palmitate, which is stable, slightly irritating, and not sensitizing at concentrations between 0.1 and $1 \%$ (CIR 1987). It has been synthesized by the esterification of palmitic acid using CALB, a lipase from Candida sp. and a modified lipase from Pseudomonas fluorescens (Ajima et al. 1986; Yin et al. 2006; Liu et al. 2012). Other vitamin A modifications include saturated fatty acid esters, oleate, lactate, and succinate/ methylsuccinate derivatives catalyzed by CALB or Rhizomucor miehei lipase (Maugard and Legoy 2000; Liu et al. 2012). Rejasse et al. (2003) proposed a vitamin A inter-esterification reaction using CALB. The first step included esterification of adipic acid with retinol in $t$-amyl alcohol, while after $24 \mathrm{~h}$, a polyol was added resulting in products with varying yields $(22-80 \%)$.

\section{Flavonoid derivatives}

Aglycon and glycosylated flavonoids are natural compounds of plant origin that have aroused interest for their anti-viral, 
anti-allergic, anti-inflammatory, anti-oxidant activities, and the protection against cardiovascular diseases and cancer (Salas et al. 2011). Their basic structure is derived from 2phenylbenzo- $\gamma$-pyran, where the original skeleton is substituted with numerous $\mathrm{OH}-$ groups that result in a considerably hydrophilic nature. The effect of acyl donors on esculin and rutin modification by CALB has been studied in microreactors offering conversion rates higher than $9.510^{-2} \mathrm{mmol}$ $\mathrm{L}^{-1} \mathrm{~h}^{-1}$ (Ardhaoui et al. 2004a). Naringin esterification in a continuous flow microreactor offered more than $85 \%$ conversion to 6-O"-monoesters. Regioselective acylation in microreactors offers mild reaction conditions, short reaction times, and high yields (Luo et al. 2013). Vinyl esters of saturated fatty acids are more reactive giving approximately a threefold increase in the conversion of naringin (Mellou et al. 2005). The enzymatic acylation of two isolated chrysoeriol glucosides by CALB resulted in products with higher anti-oxidant and anti-microbial activity against Gramnegative and Gram-positive bacteria that can be attributed to the increased interaction of the hydrophobic chain with the cell membrane due to modified lipophilicity. Irilone, chrysin, and dihydromyricetin acetate have been synthesized by Pseudomonas (syn Burkholderia) cepacia lipases and an immobilized lipase from P. expansum (Nazir et al. 2009; Chebil et al. 2007; Li et al. 2015). Orientin, vitexin, salicin fatty acid esters, and helicin butyrate have been synthesized by CALB (Liu et al. 2015; Katsoura et al. 2007). Silibyn, which occurs in nature as an equimolar mixture of two diastereoisomers (A and B) with different biological activities, has been acylated by CALB at the $\mathrm{C}-23$ position producing new antiviral and anti-tumor compounds (Gazak et al. 2010). Modification (e.g., methylation) of the $\mathrm{C}-7 \mathrm{OH}$ which bears a pro-oxidant potential significantly improves the anti-radical activity of silybin.

The nature of flavonoid and the origin of lipase are crucial for product formation. Generally, flavonoids with a primary $\mathrm{OH}$ - group on the glycosyl moiety as naringin are more reactive than those with secondary $\mathrm{OH}-$ groups only, as rutin. Chebil et al. (2007) showed that isoquercetrin, the glycosylated form of quercetin, could be acylated by both CALB and P. cepacia lipase (PSL) although only the latter could acylate quercetin. In the absence of the 4'-OH group of quercetin (hesperetin), PSL showed preference for the 7-OH group, followed by the 3'-OH group which can be explained by steric hindrance from the C-4' methoxy group. Chrysin was acylated only at the 7-OH group since the 5-OH group is not reactive when a 4-oxo group is present in the structure of the flavonoid. Molecular modeling regarding the regioselectivity of CALB showed that the aglycon part of both rutin and isoquercitrin was localized at the entrance of the enzyme's binding pocket stabilized by hydrogen bond and hydrophobic interactions (de Oliveira et al. 2009). The sugar part was placed close to the pocket bottom. Only the primary 6 '-OH group of isoquercitrin glucose and the secondary 4 "-OH group of rutin rhamnose were expected to be acetylated as they were the only ones to stabilize simultaneously near the catalytic histidine and the acetate bound to the catalytic serine. CALB synthesized monoesters on the primary $\mathrm{OH}$ of glucose moiety of esculin and on the secondary 4"'--OH of the rhamnose residue of rutin (Ardhaoui et al. 2004b). Acylation of quercetin was not achieved as the $4^{\prime}-\mathrm{OH}$ is conjugated with the C-4 carbonyl group favoring a planar formation of the molecule, which may not be suitable for the catalytic site of the enzyme (Nazir et al. 2009).

\section{Hydroxycinnamic acid derivatives}

Hydroxycinnamic acids (HCAs; ferulic, FA; $p$-coumaric, p-CA; caffeic, CA; sinapic, SA) are a class of phenylpropanoids known as more active anti-oxidants than hydroxybenzoic acids due to the presence of the $\mathrm{C}=\mathrm{COOH}$ group (Widjaja et al. 2008). They are ubiquitous in nature as a component of arabinoxylans in plant cell walls offering linkage with lignin while they present broad spectrum of biological activities including anti-bacterial, anti-viral, anti-inflammatory, anti-carcinogenic, anti-HIV, and anti-tumor effects (Tan and Shahidi 2012). However, their solubility is poor in hydrophilic and lipophilic media. Among many natural photoprotective agents, feruloylated lipids have gained attention due to their strong anti-oxidant, skin-whitening, anti-wrinkling, and UV absorptive ability (Radzi et al. 2014). FA is believed to suppress melanin generation by antagonizing tyrosine because its structure is similar to tyrosine (Chandel et al. 2011). Enzymatic synthesis of green sunscreens offers stability and selectivity in contrast with chemical synthesis that is limited due to heat sensitivity and oxidation susceptibility of FA in alkaline media. A two-step synthesis of feruloylated diacylglycerols using CALB has been proposed by Sun et al. (2007) including the transesterification of ethyl ferulate with glycerol and the subsequent transesterification of glyceryl ferulate with oleic acid offering high yield of products (up to $96 \%$ ). Esterification of FA to glyceryl ferulate by CALB has been performed in a continuous reactor reaching $80 \%$ conversion and productivity of $430 \mathrm{~kg} / \mathrm{m}^{3} /$ reactor day (Matsuo et al. 2008). Biocatalysis under vacuum-rotary evaporation contributes to increased conversion by eliminating external mass transfer resistance, effective interaction among different phases of enzymatic reaction, minimizing the negative effects of by-product ethanol (when ethyl ferulate is used as donor) on lipase activity (Xin et al. 2009). 1,3-Diferuloyl-sn-glycerol has been synthesized by CALB in a pilot plant scale bed reactor as byproduct of the transesterification of ethyl ferulate with soybean oil (Compton and Laszlo 2009). One hundred 
twenty kilograms of diferuloyl glycerol by-product could be isolated annually. Enzymatic esterification of olive, flaxseed, and fish oil offers low cost and greener configurations to the process (Ciftci and Saldana 2012; Yang et al. 2012; Radzi et al. 2014). Transesterification of ethyl ferulate with castor oil, catalyzed by CALB, yielded $62.6 \%$ lipophilic and $37.3 \%$ hydrophilic products (Sun et al. 2014). Esterification of FA with fatty (C2-C8) alcohols improves the anti-oxidant capacity towards the oxidation of HDL, LDL, and total serum. Probably, the lipophilic properties of anti-oxidants affect their incorporation into the lipid part of lipoproteins reaching the site of lipoperoxidation, accounting for the increased antioxidant activity (Jakovetic et al. 2013).

Transesterification of methyl caffeate to propyl caffeate by CALB was performed in a continuous flow packed bed microreactor offering $99.5 \%$ yield. The calculated kinetic constant $K_{m}$ was 16 times lower than than of a batch reactor (Wang et al. 2013). Caffeic acid phenethyl ester (CAPE) is a flavonoid-like compound and one of the major components of honeybee propolis possessing anti-inflammatory, anti-carcinogenic, and neuroprotective properties (Widjaja et al. 2008). High yield CAPE synthesis has been performed by CALB in a packed bed reactor, using ultrasound treatment or in one-pot reactions using organic solvents or ionic liquids (Chen et al. 2010, 2011a; Ha et al. 2012; Wang et al. 2014). One-pot synthesis of a CAPE analog, 3-cyclohexyl caffeate, has been performed by esterification of caffeoylquinic acids derived from coffee beans with methanol using a chlorogenate hydrolase followed by the transesterification of methyl caffeate with 3-cyclohecylpropyl caffeate using CALB in [Bmim] $\left[\mathrm{NTf}_{2}\right]$ (Kurata et al. 2011). Synthesized by a $C$. rugosa lipase, phytosteryl caffeate showed twofold increase in oxygen radical absorbance capacity (ORAC) comparing to the parent vinyl HCA, while phytosteryl ferulate showed a 10fold increased anti-oxidant activity compared to Trolox and a twofold increase comparing to vinyl ferulate (Tan and Shahidi 2011, 2012). Chigorimbo-Murefu et al. (2009) synthesized arbutin and hydroxyl steroid esters of FA in $t$-methyl-ethyl ether showing higher anti-oxidant activity than Trolox and their starting hydroxycinnamate. Arbutin ferulate possessed $19 \%$ higher anti-radical activity against ABTS free radical than FA and inhibited $10 \%$ more efficiently LDL oxidation than its precursors.

Although FAEs are less stable in organic media and low water content than lipases, they show higher substrate specificity (Zeuner et al. 2011). Some examples of FAE-catalyzed reactions are presented in Table 2. In 2001, Giuliani et al. succeeded for the first time the synthesis of 1-pentyl-ferulate using a FAE from Aspergillus niger in a water-in-oil microemulsions. Since then, novel FAEs from filamentous fungi such as Fusarium oxysporum, Myceliophthora thermophila (syn Sporotrichum thermophile), and
Talaromyces stipitatus have been employed in detergentless microemulsions for the transesterification of methyl donors to alkyl hydroxycinnamates, feruloylated-arabinooligosaccharides showing regioselectivity for the primary hydroxyl group of the non-reducing arabinofuranose ring and other sugar ferulates (Topakas et al. 2003a; Vafiadi et al. $2005,2006,2007 b, 2008 a)$. Although esterification with fatty alcohols generally results in more lipophilic products, the glyceryl esters of HCAs have been proved more hydrophilic than their donors. Fed-batch esterification of FA with diglycerin was performed by a FAE from A. niger under reduced pressure yielding $69 \%$ feruloyl and $21 \%$ diferuloyl diglycerols (Kikugawa et al. 2012). The major product (FADG1) showed highest water solubility while all products maintained their radical scavenging activity against DPPH and their UV absorption properties. Diferuloyl diglycerols showed a twofold increase of anti-oxidant activity comparing to feruloyl diglycerols and FA. Esterification of SA and $p$-CA with glycerol yielded $70 \%$ glycerol sinapate and $60 \%$ glycerol- $p$-coumarate, respectively, with indication of the formation of minor dicinnamoyl glycerol esters (Tsuchiyama et al. 2007). The ability of glycerol sinapate to scavenge DPHH radicals was higher than BHT while it maintained its UV absorption properties.

\section{Galloyl derivatives}

Tannins, natural occurring polyphenols that can be found in pine and spruce bark, vegetables, and fruits, are categorized into hydrolysable, condensed, and complex. The simplest hydrolysable tannins, commonly named gallotannins, consist of gallic acid molecules esterified to a core polyol. The biocatalytic synthesis of gallic acid esters is performed mainly by tannases and may follow different routes: (1) hydrolysis of tannic acid into gallic acid and further esterification to galloyl esters, (2) direct esterification of tannic acid into a galloyl ester, or (3) transesterification of galloyl esters into another ester. Examples of tannase-based reactions are presented in Table 3. A well-known synthetic galloyl ester widely used in skin cleaning/care products, make up, sunscreen, and tanning products is propyl gallate. Its biological activities are not limited to the free-radical scavenging ability as it exhibits antimicrobial, anti-nociceptive activity, ultraviolet (UV) radiation protection, anti-cariogenesis, anti-mutagenesis, and anticarcinogenesis effects. However, in cosmetic formulations, its concentration is low (up to $0.1 \%$ ) due to indications for skin irritation or sensitization (CIR 2007). Applications of propyl gallate expand into the food, pharmaceutical, adhesive, lubricant, and biodiesel industry where it has been used as an anti-oxidant additive, for more than 20 years (Zhang 2015).

The majority of tannases used for the synthesis of propyl gallate are carrier-bound or modified. A mycelium-bound tannase from $A$. niger esterified gallic acid at $65 \%$ yield ( $\mathrm{Yu}$ 
Table 2 Ferulic acid esterase-catalyzed reactions

\begin{tabular}{|c|c|c|c|c|c|c|c|}
\hline Product & Donor & Acceptor & Enzyme & Solvent system & Yield (time) & $\begin{array}{l}\mathrm{T} \\
\left({ }^{\circ} \mathrm{C}\right)\end{array}$ & Reference \\
\hline 1-Pentyl ferulate & Ferulic acid & 1-Pentanol & FAEA & $\begin{array}{l}\text { CTAB: hexane: } \\
\text { pentanol: buffer }\end{array}$ & $60 \%$ (n.q.) & 40 & $\begin{array}{l}\text { Giuliani et al. } \\
2001\end{array}$ \\
\hline 1-Butyl ferulate & Methyl ferulate & 1-Butanol & $\begin{array}{l}\text { CLEAs } \\
\text { immobilized } \\
\text { Ultraflo L }\end{array}$ & $\begin{array}{l}\text { Hexane: 1-butanol: } \\
\text { buffer }\end{array}$ & $97 \%(144 \mathrm{~h})$ & 37 & $\begin{array}{l}\text { Vafiadi et al. } \\
\text { 2008a }\end{array}$ \\
\hline 1-Butyl sinapate & Methyl sinapate & 1-Butanol & AnFaeA & $\begin{array}{l}\text { Hexane: 1-butanol: } \\
\text { buffer }\end{array}$ & $78 \%(120 h)$ & 35 & $\begin{array}{l}\text { Vafiadi et al. } \\
2008 b\end{array}$ \\
\hline 2-Butyl sinapate & Methyl sinapate & 2-Butanol & AnFaeA & $\begin{array}{l}\text { Hexane: 2-butanol: } \\
\text { buffer }\end{array}$ & $9 \%(120 \mathrm{~h})$ & 37 & $\begin{array}{l}\text { Vafiadi et al. } \\
2008 \mathrm{a}\end{array}$ \\
\hline 1-Butyl caffeate & Methyl caffeate & 1-Butanol & StFae-A & $\begin{array}{l}\text { Hexane: 1-butanol: } \\
\text { buffer }\end{array}$ & Up to $25 \%(144 \mathrm{~h})$ & 35 & $\begin{array}{l}\text { Topakas et al. } \\
2004\end{array}$ \\
\hline 1-Butyl- $p$-coumarate & Methyl $p$-coumarate & 1-Butanol & FoFae-I & $\begin{array}{l}\text { Hexane: 1-butanol: } \\
\text { buffer }\end{array}$ & Up to $70 \%(144 \mathrm{~h})$ & 35 & $\begin{array}{l}\text { Topakas et al. } \\
\text { 2003a }\end{array}$ \\
\hline $\begin{array}{l}\text { 1-Propyl-p- } \\
\text { hydroxyphenylacetate }\end{array}$ & $\begin{array}{l}p \text {-Hydroxyphenylacetic } \\
\text { acid }\end{array}$ & 1-Propanol & FoFae-II & $\begin{array}{l}\text { Hexane: } 1- \\
\text { propanol: buffer }\end{array}$ & $75 \%(224 \mathrm{~h})$ & 30 & $\begin{array}{l}\text { Topakas et al. } \\
2003 \mathrm{~b}\end{array}$ \\
\hline $\begin{array}{l}\text { 1-Propyl- } p \text { - } \\
\text { hydroxylphenylpropio- } \\
\text { nate }\end{array}$ & $\begin{array}{l}p \text { - } \\
\text { Hydroxylphenylpropio- } \\
\text { nic acid }\end{array}$ & & & & $70 \%(224 \mathrm{~h})$ & & \\
\hline Glycerol sinapate & $\begin{array}{l}\text { Sinapic acid } \\
\text { Methyl sinapate }\end{array}$ & Glycerol & AnFaeA & $\begin{array}{l}{\left[\mathrm{C}_{5} \mathrm{OHmim}\right]\left[\mathrm{PF}_{6}\right] \text { buffer }} \\
\text { b }\end{array}$ & $\begin{array}{c}76.7 \%(24 \mathrm{~h}) \\
\text { Up to } 7 \%(120 \mathrm{~h})\end{array}$ & 50 & $\begin{array}{l}\text { Vafiadi et al. } \\
2009\end{array}$ \\
\hline Glycerol ferulate & Ferulic acid & Glycerol & FAE-PL & $\begin{array}{l}\text { Glycerol: DMSO: } \\
\text { buffer }\end{array}$ & $81 \%$ (n.q.) & 50 & $\begin{array}{l}\text { Tsuchiyama } \\
\text { et al. } 2006\end{array}$ \\
\hline $\begin{array}{l}\text { Diglycerol ferulates } \\
\text { (mixture of isomers) }\end{array}$ & Ferulic acid & Diglycerin S & FAE-PL & $\begin{array}{l}\text { Diglycerin S: } \\
\text { DMSO: buffer }\end{array}$ & $95 \%(12 \mathrm{~h})$ & 50 & $\begin{array}{l}\text { Kikugawa et al. } \\
2012\end{array}$ \\
\hline Glycerol $p$-coumarate & $p$-Coumaric acid & Glycerol & FAE-PL & $\begin{array}{l}\text { Glycerol: DMSO: } \\
\text { buffer }\end{array}$ & $\sim 60 \%(72 \mathrm{~h})$ & 50 & $\begin{array}{l}\text { Tsuchiyama } \\
\text { et al. } 2007\end{array}$ \\
\hline$L$-Arabinose ferulate & $\begin{array}{l}\text { Methyl ferulate } \\
\text { Ethyl ferulate }\end{array}$ & $L$-Arabinose & StFae-C & $\begin{array}{l}\text { Hexane: } t \text {-butanol: } \\
\text { buffer }\end{array}$ & $\begin{array}{c}\text { Up to } 50 \%(120 \mathrm{~h}) \\
6.3 \%(-)\end{array}$ & 35 & $\begin{array}{l}\text { Vafiadi et al. } \\
2005\end{array}$ \\
\hline$D$-Arabinose ferulate & Methyl ferulate & $D$-Arabinose & & $\begin{array}{l}\text { Hexane: } t \text {-butanol: } \\
\text { buffer }\end{array}$ & $45 \%(-)$ & 35 & $\begin{array}{l}\text { Vafiadi et al. } \\
2007 \mathrm{a}\end{array}$ \\
\hline & Ferulic acid & $D$-Arabinose & Multifect P3000 & Hexane: $1-$ & $36.7 \%(144 \mathrm{~h})$ & 35 & Couto et al. \\
\hline$D$-Galactose ferulate & Ferulic acid & $D$-Galactose & Depol 670 & butanol:buffer & $61.5 \%(144 \mathrm{~h})$ & & 2010 \\
\hline$D$-Xylose ferulate & Ferulic acid & D-Xylose & & $\begin{array}{l}\text { Hexane: } 2- \\
\quad \text { butanone:buffer }\end{array}$ & $37.3 \%(144 \mathrm{~h})$ & & \\
\hline Feruloyl raffinose & Ferulic acid & Raffinose & Depol 740L & $\begin{array}{l}\text { Hexane: 2- } \\
\text { butanone:buffer }\end{array}$ & $11.9 \%$ (7 days) & 35 & $\begin{array}{l}\text { Couto et al. } \\
2011\end{array}$ \\
\hline Feruloyl galactobiose & Ferulic acid & Galactobiose & & $\begin{array}{l}\text { Hexane: 1,4- } \\
\quad \text { dioxane:buffer }\end{array}$ & $26.8 \%(144 \mathrm{~h})$ & & \\
\hline Feruloyl xylobiose & Ferulic acid & Xylobiose & & Hexane: 2- & $9.4 \%(144 \mathrm{~h})$ & & \\
\hline Feruloyl arabinodiose & Ferulic acid & Arabinodiose & & butanone:buffer & $7.9 \%(144$ h) & & \\
\hline Feruloyl sucrose & Ferulic acid & Sucrose & & & $13.2 \%$ (n.q.) & & \\
\hline Feruloyl FOS & Ferulic acid & FOS & & & $9.6 \%$ (n.q.) & & \\
\hline
\end{tabular}

FAEA: FAE from Aspergillus niger; Ultraflo L, Depol 740L: multi-enzymatic preparation from Humicola insolens; AnFaeA: type A FAE from A. niger; StFae-A, StFae-C: FAE from Sporotrichum thermophile ATCC 34628; FoFae-I, FoFae-II: FAE from Fusarium oxysporum; FAE-PL: FAE from A. niger purified from the commercial preparation Pectinase PL“Amano"; Multifect P3000: multi-enzymatic preparation from Bacillus amyloliquefaciens; Depol 670: multi-enzymatic preparation from Trichoderma reesei

et al. 2007), whereas its microencapsulation by a chitosanalginate complex showed more moderate results ( $\mathrm{Yu}$ and $\mathrm{Li}$ 2005). Mycelia could protect the enzyme from the harshness of organic solvents as an immobilization matrix does and offer avoidance of costly and time-consuming purifications. Tannases from Aspergillus species, Lactobacillus plantarum, and Emericella nidulans immobilized on different carriers, catalyzed the esterification of tannic acid in organic and aqueous media offering high yields (43-88\%) (Fernandez-Lorente et al. 2011; Prasad et al. 2011; Nie et al. 2012a; Goncalves et al. 2013). A bioimprinted commercial tannase esterified tannic acid with propanol resulting in $50 \%$ yield increase compared to the non-imprinted enzyme. Bioimprinting locks the enzyme into a favorable conformation for catalysis during lyophilization through the addition of the targeted substrate prior to freezing. Moreover, the ligand may impede the formation of inactive "microconformations" in the active site (Aithal and Belur 2013). Bioimprinting methods can activate tannase remarkably offering a 100 -fold increase of conversion (Nie et al. 2012b). Techniques such as pH tuning, interfacial activation, and cryogenic protection have been applied (Nie et al. 2012a, 2014). Free tannases from Aspergillus species, 


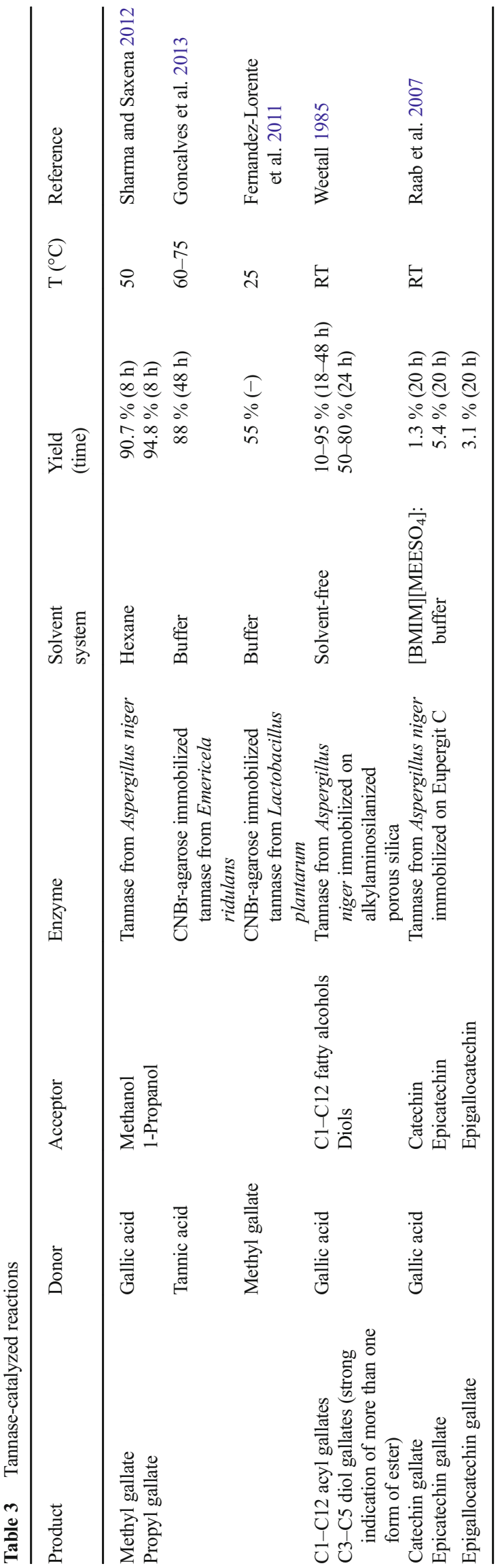

Penicillium variable, and Bacillus massiliensis (whole-cell) have synthesized propyl gallate in organic solvents (Yu and Li 2008; Sharma and Gupta 2003; Sharma and Saxena 2012; Beena et al. 2011). Regarding other galloyl esters, Toth and Hensler (1952) reported the synthesis of methyl and ethyl esters but not the phenyl ester of gallic acid in the presence of tannase dissolved in buffer, revealing for the first time the ability of soluble tannases to esterify. Gallic acid esters were synthesized by an immobilized tannase from $A$. niger performing esterification of gallic acid with alcohols (C1$\mathrm{C} 12)$ and with several diols. This system proved that the enzyme had broad specificity for alcohols but absolute specificity for the acid moiety (Weetall 1985).

Representing proanthocyanidin monomers, green tea catechins mainly comprising of epicatechins (ECs), epigallocatechins (EGCs), epicatechin gallate (ECG), and epigallocatechin gallate (EGCG) have gained attention for their strong anti-oxidant and cardiovascular protective activity. Green tea is considered a useful agent for promoting skin regeneration or treatment for psoriasis, rosacea, and actinic keratosis and repairs UV-damaged skin in vivo, which leads to the improvement of wrinkles (Hong et al. 2012). EGCG is an anti-inflammatory and anti-irritant anti-oxidant, which is responsible for health benefits like the stimulation of collagen production while reducing oxidative damage within the skin. EGCG vehiculated in cosmetic formulations presents good skin penetration and retention favoring its skin effects (dal Belo et al. 2009). Among epicatechin derivatives, EGC is the most effective photoprotector, following in a descending order by EGCG, EC, and ECG (Hong et al. 2013). However, it is present in natural green tea preparations in low amounts compared to EGCG, which is the most abundant catechin in green tea (Cao and Ito 2004). Low-yield galloylation of epicatechins has been achieved by an immobilized commercial tannase from A. niger in ionic liquids (Raab et al. 2007). It is evident that tannases could be proved to be a powerful biocatalyst in order to modify the active constituents of green tea and synthesize tailor-made compounds with preferred biological activities for use in different cosmeceutical products. High yield acetylation of catechin and ECGG has been reported using commercial lipases from $R$. miehei and $P$. cepacia (Lambusta et al. 1993; Zhu et al. 2014).

\section{Proteases}

Besides catalyzing the cleavage of peptide bonds for the production of peptide cosmeceuticals, proteases (EC 3.4) find application in transesterification reactions in organic solvents, lowering the cost of ester production and increasing reaction specificity. Enzymes from different sources display different features; for example, contrary to serine proteases, thermolysin (a metallo-protease from Bacillus 
thermoproteolyticus) is not generally used in transesterifications (Pedersen et al. 2002). Studies have proved that the S1 pocket of thermolysin active site can bind medium and large hydrophobic amino acids, suggesting that the vinyl group can bind as well, allowing the possibility of using thermolysin for the synthesis of sugar esters. For these reasons, the use of proteases for ester production in the cosmetic field is of great interest and potential (Fornbacke and Clarsund 2013). The main compounds synthesized by proteases are summarized in Table 4.

As a typical flavonoid glycoside with anti-oxidant activity, rutin has been enzymatically esterified with different acyl donors to enhance its solubility and stability in lipophilic media. The regioselective transesterification of rutin with divinyl carboxylates in pyridine was performed at $50^{\circ} \mathrm{C}$ for 4 days by an alkaline protease from B. subtilis (Xiao et al. 2005). Only 3"$O$-substituted rutin ester was obtained in these conditions showing that regioselective acylation can be controlled by regulation of solvents and enzymes. Pre-irradiated alkaline protease from $B$. subtilis increased transesterification of troxerutin with divinyl dicarboxylates by $31 \%$ in pyridine using an ultrasound bath ( $150 \mathrm{~W}$ and $80 \mathrm{kHz}$ ) (Xiao et al. 2011). Ultrasonic treatment is an environmentally benign method based on the cavitation phenomenon, which causes the formation, expansion, and collapse of cavities generating high temperatures and pressures of the neighboring surroundings (Khan and Rathod 2015). Thus, cavitation can accelerate enzymatic reactions maintaining ambient conditions of the overall environment. Ultrasonic treatment represents an efficient route of performing transterification in order to modify solubility of anti-oxidant molecules.

Arbutin derivative with undecylenic acid located at its sugar moiety has been enzymatically synthesized using an alkaline protease from $B$. subtilis in a mixture of dimethylformamide and water (95:5) (Tokiwa et al. 2007a). The produced arbutin undecylenic acid ester showed to inhibit the activity of tyrosinase from mushroom; in addition, the arbutin ester seemed to have high dermal absortion and did not show the peculiar smell of undecylenic acid which commonly prevents its application in cosmetics. Further studies have proven that after 6 days of incubation of B16 melanoma cells with arbutin undecylenic ester, melanin production levels were decreased to approximately $30 \%$ compared with that of the control cells (Tokiwa et al. 2007b). Alkaline protease from B. subtilis was also applied in regioselective esterification of the hydroxyl group at C-7 position of kojic acid to produce diverse lipophilic kojic acid esters in dimethylformamide (Raku and Tokiwa 2003). Kojic acid esters were effective as scavengers against DPPH radical, and they are expected to prevent oxidational stress in vivo. Moreover, their

Table 4 Protease-catalyzed reactions

\begin{tabular}{|c|c|c|c|c|c|c|c|}
\hline Product & Donor & Acceptor & Enzyme & Solvent system & Yield (time) & $\begin{array}{l}\mathrm{T} \\
\left({ }^{\circ} \mathrm{C}\right)\end{array}$ & Reference \\
\hline $\begin{array}{l}\text { 7-O-Vinyl adipoyl kojic } \\
\text { acid }\end{array}$ & Kojic acid & Divinyl adipate & $\begin{array}{l}\text { Bioprase from } \\
\text { Bacillus }\end{array}$ & Dimethylformamide & $25 \%$ (7 days) & 30 & $\begin{array}{l}\text { Raku and } \\
\text { Tokiwa }\end{array}$ \\
\hline $\begin{array}{l}\text { 7-O-Hexanoyl/octanoyl/ } \\
\text { decanoyl kojic acid }\end{array}$ & & $\begin{array}{l}\text { Vinyl hexanoate/ } \\
\text { octanoate/ } \\
\text { decanoate }\end{array}$ & subtilis & & $\begin{array}{l}13-27 \% \\
\quad(7 \text { days })\end{array}$ & & 2003 \\
\hline $\begin{array}{l}\text { 6-O-Undecylenoyl p- } \\
\text { hydroxyphenyl } \beta \text {-D- } \\
\text { glucopyranoside }\end{array}$ & Arbutin & $\begin{array}{l}\text { Undecylenic acid } \\
\text { vinyl ester }\end{array}$ & $\begin{array}{l}\text { Bioprase from } \\
\text { Bacillus } \\
\text { subtilis }\end{array}$ & Dimethylformamide & $62 \%$ (7 days) & 40 & $\begin{array}{l}\text { Tokiwa et } \\
\text { al. } \\
2007 b\end{array}$ \\
\hline $\begin{array}{l}3 "-O \text {-Vinylsuccinyl or } \\
\text { vinylsebacoyl-rutin }\end{array}$ & Rutin & $\begin{array}{l}\text { Divinyl succinate/ } \\
\text { sebacate }\end{array}$ & $\begin{array}{l}\text { Subtilisin from } \\
\text { Bacillus } \\
\text { subtilis }\end{array}$ & Pyridine & $\begin{array}{l}12.8 / 19.8 \% \\
(4 \text { days })\end{array}$ & 50 & $\begin{array}{l}\text { Xiao et al. } \\
2005\end{array}$ \\
\hline $\begin{array}{l}\text { Vinylsuccinyl/ } \\
\text { vinylglutaryl/ } \\
\text { vinyladipoyl// } \\
\text { dinylnonanedioyl/ } \\
\text { vinylsebacoyl// } \\
\text { vinyltridecanedioyl- } \\
\text { troxerutin }\end{array}$ & Troxerutin & $\begin{array}{l}\text { Divinyl succinate/ } \\
\text { glutarate/ } \\
\text { adipate/ } \\
\text { nonanedioate/ } \\
\text { sebacate/ } \\
\text { decanedioate }\end{array}$ & $\begin{array}{l}\text { Subtilisin from } \\
\text { Bacillus } \\
\text { subtilis(- } \\
\text { enzyme pre- } \\
\text { irradiated) }\end{array}$ & Pyridine & $\begin{array}{l}10.6-33.10 \% \\
\quad(4 \mathrm{~h})\end{array}$ & 50 & $\begin{array}{c}\text { Xiao et al. } \\
2011\end{array}$ \\
\hline 2-O-Lauroyl-sucrose & Sucrose & Vinyl laurate & $\begin{array}{l}\text { Alkaline } \\
\text { protease from } \\
\text { Bacillus } \\
\text { pseudofirmus }\end{array}$ & Dimethylformamide:pyridine & $\begin{array}{c}50-60 \% \\
(24 \mathrm{~h})\end{array}$ & 45 & $\begin{array}{l}\text { Pedersen } \\
\text { et al. } \\
2003\end{array}$ \\
\hline $\begin{array}{l}\text { 6-O-Vinyladipoyl-D- } \\
\text { glucose/-D-mannose/-D- } \\
\text { galactose/-methyl D- } \\
\text { galactoside }\end{array}$ & $\begin{array}{l}\text { D-Glucose/D- } \\
\text { mannose/D- } \\
\text { galactose/ } \alpha \text { - } \\
\text { methyl D- } \\
\text { galactoside }\end{array}$ & Divinyl adipate & $\begin{array}{l}\text { Alkaline } \\
\text { protease from } \\
\text { Streptomyces } \\
\text { sp. }\end{array}$ & Dimethylformamide & $\begin{array}{l}49-74 \% \\
\quad(7 \text { days })\end{array}$ & 35 & $\begin{array}{l}\text { Kitagawa } \\
\text { et al. } \\
1999\end{array}$ \\
\hline
\end{tabular}


Table 5 Transferase catalyzed reactions

\begin{tabular}{|c|c|c|c|c|c|c|c|}
\hline Product & Donor & Acceptor & Enzyme & $\begin{array}{l}\text { Solvent } \\
\text { system }\end{array}$ & Yield (time) & $\begin{array}{l}\mathrm{T} \\
\left({ }^{\circ} \mathrm{C}\right)\end{array}$ & Reference \\
\hline $\begin{array}{c}\text { EGCG glycosides (EGCG-G1, } \\
\text { EGCG-G2A, EGCG-G2B) }\end{array}$ & Sucrose & EGCG & $\begin{array}{l}\text { Glucansucrase from } \\
\text { Leuconostoc mesenteroides }\end{array}$ & Buffer & $62.2 \%(6.5 \mathrm{~h})$ & 28 & Moon et al. 2006a \\
\hline $\begin{array}{l}\text { EC glycosides (EC3A, EC3B, } \\
\text { EC3C, EC4A) }\end{array}$ & $\begin{array}{l}\beta- \\
\text { Cyclode- } \\
\text { xtrin }\end{array}$ & $\begin{array}{l}(-)- \\
\text { Epicatechin }\end{array}$ & $\begin{array}{l}\beta \text {-Cyclodextrin transferase } \\
\text { from Paenibacillus sp. }\end{array}$ & Buffer & $18.1 \%(24 \mathrm{~h})$ & 50 & $\begin{array}{l}\text { Aramsangtienchai } \\
\text { et al. } 2011\end{array}$ \\
\hline $\begin{array}{l}\text { Catechin } 3^{\prime}-\mathrm{O}-\alpha-\mathrm{D}- \\
\text { glucopyranoside }\end{array}$ & Maltose & $(+)$-Catechin & $\begin{array}{l}\text { Glycosyltransferase from } \\
\text { Streptococcus sobrinus }\end{array}$ & Buffer & $13.7 \%(24 \mathrm{~h})$ & 45 & $\begin{array}{l}\text { Nakahara et al. } \\
1995\end{array}$ \\
\hline $\begin{array}{l}\text { Catechin } 3^{\prime}-\mathrm{O}-\alpha-\mathrm{D}- \\
\text { glucopyranoside (main product) }\end{array}$ & Starch & & $\begin{array}{l}\text { Cyclodextrin } \\
\text { glucanotransferase from } \\
\text { Bacillus macerans }\end{array}$ & & $18.3 \%(40 \mathrm{~h})$ & 40 & $\begin{array}{l}\text { Funayama et al. } \\
1993\end{array}$ \\
\hline $\begin{array}{l}\text { Catechin 3'-O- } \alpha \text {-D- } \\
\text { glucopyranoside }\end{array}$ & Maltose & & $\begin{array}{l}\text { Enzyme with transfer activity } \\
\text { from Xanthomonas } \\
\text { campestris WU-9701 }\end{array}$ & & $57.1 \%(36 \mathrm{~h})$ & 45 & Sato et al. 2000 \\
\hline Hydroquinone fructoside & Sucrose & Hydroquinone & $\begin{array}{l}\text { Levansucrase from } \\
\text { Leuconostoc mesenteroides }\end{array}$ & Buffer & $14 \%(6 h)$ & 28 & Kang et al. 2009 \\
\hline \multirow[t]{2}{*}{$\beta$-Arbutin- $\alpha$-G1/ $\beta$-arbutin- $\alpha$-G2 } & Sucrose & $\beta$-Arbutin & $\begin{array}{l}\text { Glucansucrase from } \\
\text { Leuconostoc mesenteroides } \\
\text { B-1299B }\end{array}$ & Buffer & $27.1 \%(10 \mathrm{~h})$ & 28 & Moon et al. 2007a \\
\hline & Starch & $\beta$-Arbutin & $\begin{array}{l}\text { Cyclomaltodextrin } \\
\text { glucanotransferase from }\end{array}$ & Buffer & $70 \%(16 \mathrm{~h})$ & 40 & $\begin{array}{l}\text { Sugimoto et al. } \\
2003\end{array}$ \\
\hline$\alpha$-Arbutin- $\alpha$-G1/ $\beta$-arbutin- $\alpha$-G2 & & $\alpha$-Arbutin & Bacillus macerans & Buffer & $70 \%(16 h)$ & 40 & $\begin{array}{l}\text { Sugimoto et al. } \\
2005\end{array}$ \\
\hline$\alpha$-Arbutin & Sucrose & Hydroquinone & $\begin{array}{l}\text { Amylosucrase from } \\
\text { Deinococcus geothermalis }\end{array}$ & Buffer & $90 \%(24$ h) & 35 & Seo et al. $2012 \mathrm{a}$ \\
\hline $\begin{array}{l}\alpha \text {-Arbutin (in a mixture of } \\
\text { products, } \mathrm{G} 2-\mathrm{G} 7 \text { ) }\end{array}$ & $\begin{array}{l}\alpha- \\
\text { Cyclode- } \\
\text { xtrin }\end{array}$ & & $\begin{array}{l}\text { Cyclodextrin glycosyltranferase } \\
\text { from Thermoanaerobacter } \\
\text { sp. (Toruzyme } 3.0 \mathrm{~L} \text {; after } \\
\text { amyloglucosidase treatment) }\end{array}$ & Buffer & $30.0 \%(24 \mathrm{~h})$ & 40 & $\begin{array}{l}\text { Mathew and } \\
\text { Adlercreutz } \\
2013\end{array}$ \\
\hline$\beta$-Arbutin- $\alpha$-glycoside & Sucrose & $\beta$-Arbutin & $\begin{array}{l}\text { Amylosucrase from } \\
\text { Deinococcus geothermalis } \\
\text { DSM } 11300\end{array}$ & Buffer & $98 \%(-)$ & 35 & Seo et al. 2009 \\
\hline $\begin{array}{l}\text { Kojic acid glycosides }(5-O-\alpha \text {-D- } \\
\text { and } 7-O-\alpha \text {-D-glucopyranoside) }\end{array}$ & & Kojic acid & $\begin{array}{l}\text { Sucrose phosphorylase from } \\
\text { Leuconostoc mesenteroides }\end{array}$ & DMSO:buffer & $19.7 \%(24 \mathrm{~h})$ & 42 & $\begin{array}{l}\text { Kitao \& Serine } \\
\quad 1994\end{array}$ \\
\hline $\begin{array}{l}\text { Quercetin glycosides (3'-O- } \alpha \text {-D } \\
\text { and 4- } O-\alpha \text {-D glycopyranoside) }\end{array}$ & & Quercetin & $\begin{array}{l}\text { Glucansucrase from } \\
\text { Leuconostoc mesenteroides }\end{array}$ & Acetone & $23.1 \%(5 \mathrm{~h})$ & 28 & Moon et al. 2007b \\
\hline $\begin{array}{l}\text { Ampelopsin glycosides up to } \\
5 \text { units }\left(4^{\prime}-O-\alpha \text {-D- }\right. \\
\text { glycopyranoside as main } \\
\text { product) }\end{array}$ & & Ampelopsin & $\begin{array}{l}\text { Dextransucrase from } \\
\text { Leuconostoc mesenteroides }\end{array}$ & $\begin{array}{l}\text { DMSO: } \\
\quad \text { buffer }\end{array}$ & $87.3 \%(1 \mathrm{~h})$ & 28 & Woo et al. 2012 \\
\hline $\begin{array}{l}\text { Astragalin glycosides (kaempferol- } \\
\text { 3-O- } \beta \text {-D-isomaltoside, 3-O- } \beta \text { - } \\
\text { D-nigeroside, polymerized 3-O- } \\
\beta \text {-D-isomaltooligosaccharides) }\end{array}$ & Sucrose & Astragalin & & & $24.5 \%(5 \mathrm{~h})$ & 28 & Kim et al. 2012 \\
\hline $\begin{array}{l}\text { Ascorbic acid glycosides }(2-O-\alpha- \\
\text { D-glucopyranosyl L-ascorbic } \\
\text { acid as main product) }\end{array}$ & $\begin{array}{l}\alpha- \\
\text { Cyclode- } \\
\text { xtrin }\end{array}$ & Ascorbic acid & $\begin{array}{l}\text { Cyclomaltodextrin } \\
\text { glucanotransferase form } \\
\text { Bacillus stearothermophilus }\end{array}$ & Buffer & $45.6 \%(1 \mathrm{~h})$ & 60 & Aga et al. 1991 \\
\hline $\begin{array}{l}\text { Benzoyl glycosides (1-O-benzoyl- } \\
\alpha \text {-D-, } 2 \text {-O-benzoyl- } \alpha \text {-D- and 2- } \\
\text { O-benzoyl- } \beta \text {-D- } \\
\text { glucopyranoside) }\end{array}$ & Sucrose & Benzoic acid & $\begin{array}{l}\text { Sucrose phosphorylase from } \\
\text { Streptococcus mutans }\end{array}$ & Buffer & $70 \%(48 \mathrm{~h})$ & 37 & $\begin{array}{l}\text { Sugimoto et al. } \\
2007\end{array}$ \\
\hline
\end{tabular}

biodegradability exceeded $60 \%$, allowing their application in cosmetics for the production of eco-friendly and oil-based product products.

\section{Transferases}

A broad variety of bioactive glycosides has been synthesized using glycosyltransferases (GTFs; EC 2.4); enzymes that catalyze the transfer of sugar moieties from an activated donor to specific acceptors forming glycosidic bonds. Novel EGCG mono- and di-glycosides with increased UV irradiation stability, browning resistance, and water solubility regardless of the position or linkage of the glycosylation have been synthesized by transferases from L. mesenteroides (Kitao et al. 1995; Moon et al. 2006a). EC mono-, di-, and tri-glycosides have been synthesized by a $\beta$-cyclodextrin glucosyltransferase from Paenibacillus sp. while various catechin derivatives by 
amylosucrases from Deinococcus geothermalis, Streptoco ccus sobrinus, a cyclodextrin glucanotransferase from Bacillus macerans and an enzyme with glycosyl transfer activity from Xanthomonas campestris (Aramsangtienchai et al. 2011; Cho et al. 2011; Nakahara et al. 1995; Funayama et al. 1993; Sato et al. 2000). Transferase-based modification of hydroquinone has been focused on its glycosylation or the production of arbutin ( $\alpha$ - and $\beta$-) glycosides. A two-step synthesis of $\alpha$-arbutin including prior treatment of $\alpha$-cyclodextrin with an amyloglucosidase from $A$. niger and subsequent transfer reaction using a commercial cyclodextrin glucano transferase from Thermoanaerobacter $\mathrm{sp}$. has been reported (Mathew and Adlercreutz 2013). Before treatment, hydroquinone was glycosylated with up to 7 glucose units while after treatment, $\alpha$-arbutin was an absolute product. Results on the synthesis of arbutin glycosides show that the $\alpha$-glucosidic linkage plays an important role in the inhibitory effect on human tyrosinase (Sugimoto et al. 2005).

2-O- $\alpha$-D-glycopyranosyl L-ascorbic acid has been synthesized by a cyclomaltodextrin glucanotransferase from Bacillus stearothermophilus and a sucrose phosphorylase from Bifidobacterium longum (Aga et al. 1991; Kwon et al. 2007). The first transglycosylation of CA was performed by a sucrose phosphorylase from $\mathrm{B}$. longum in aqueous $\mathrm{CO}_{2}$ supercritical media resulting in the formation of caffeic mono- and di-glycosides (Shin et al. 2009). Ampelopsin is a flavonoid with numerous activities such as anti-inflammatory, anti-microbial, anti-oxidant, anti-hypertension, hepatoprotective, anti-carcinogenic, anti-viral, and skin-whitening effects. A dextransucrase from $L$. mesenteroides synthesized a mixture of novel ampelopsin glycosides with up to 5 attached glycoside units. The primary product, ampelopsin-4'-O- $\alpha$-Dglucopyranoside, reached an optimal yield of $34 \mathrm{~g} / \mathrm{L}$ while it showed an 89-fold increase in water solubility, 14.5-fold increase in browning resistance comparing to ampelopsin, and 10-fold higher tyrosinase inhibition comparing to $\beta$-arbutin. Browning resistance was similar to ECGC glycosides and anti-oxidant activity superior to ampelopsin (Woo et al. 2012). Another major flavonoid found in plants, astragalin, was modified by a dextransucrase from $L$. mesenteroides giving products with increased inhibitory effects on matrix metalloproteinase-1 expression, anti-oxidant effect, and melanin inhibition (Kim et al. 2012). Quercetin glycosides were synthesized by a glucansucrase from $L$. mesenteroides showing increased water solubility, slower scavenging activity, and no improvement in tyrosinase inhibition (Moon et al. 2007b). Three main benzoyl and two main kojic acid glycosides were synthesized by a sucrose phosphorylase from Streptococcus mutans and L. mesenteroides, respectively (Sugimoto et al. 2007; Kitao and Serine 1994). Examples of transferase catalyzed reactions are presented in Table 5 .

\section{Glucosidases}

Glucosidases, such as $\alpha$ - (EC 3.2.1.20) and $\beta$-glucosidases (EC 3.2.1.21), are a group of enzymes that hydrolyze individual glucosyl residues from various glycoconjugates including $\alpha$ - or $\beta$-linked polymers of glucose under physiological conditions. However, these enzymes are able to synthesize a broad variety of sugar derivatives under defined conditions in two different manners: transglycosylation or reverse hydrolysis (Park et al. 2005). Active compounds that have been obtained by enzyme-catalyzed glucosidation include vitamin and arbutin derivatives as presented in Table 6 . Pharmacological properties of vitamin E can be improved by increasing its water solubility, absorbtivity and stability through glycosylation. A novel water-soluble vitamin E derivative, $2-(\alpha-D$-glucopyranosyl)methyl-2,5,7,8tetramethylchroman-6-ol (TMG) has been synthesized from

Table 6 Glucosidase-catalyzed reactions

\begin{tabular}{|c|c|c|c|c|c|c|c|}
\hline Product & Donor & Acceptor & Enzyme & $\begin{array}{l}\text { Solvent } \\
\text { system }\end{array}$ & Yield (time) & $\begin{array}{l}\mathrm{T} \\
\left({ }^{\circ} \mathrm{C}\right)\end{array}$ & Reference \\
\hline $\begin{array}{l}\text { 4-Hydroxyphenyl- } \beta \text { - } \\
\text { isomaltoside }\end{array}$ & Sucrose & Arbutin & $\begin{array}{l}\alpha \text {-Glucosidase from } \\
\text { Saccharomyces } \\
\text { cerevisiae }\end{array}$ & Buffer & $50 \%(20 \mathrm{~h})$ & 40 & $\begin{array}{l}\text { Milosavić } \\
\text { et al. } \\
2007\end{array}$ \\
\hline $\begin{array}{l}\text { Hydroquinone } \alpha \text {-D- } \\
\text { glucopyranoside }\end{array}$ & Maltose & Hydroquinone & $\begin{array}{l}\alpha \text {-Glucosidase from } \\
\text { Saccharomyces }\end{array}$ & Buffer & $13 \%(20 \mathrm{~h})$ & 30 & $\begin{array}{l}\text { Prodanović } \\
\text { et al. }\end{array}$ \\
\hline $\begin{array}{l}\text { Hydroquinone } \alpha \text {-D- } \\
\text { isomaltoside }\end{array}$ & & & cerevisiae & & $15 \%(20 \mathrm{~h})$ & & 2005 \\
\hline $\begin{array}{l}\text { 2-( } \alpha \text {-D- } \\
\text { Glucopyranosyl)methyl- } \\
\text { 2,5,7,8-tetramethylchroman- } \\
\text { 6-ol }\end{array}$ & Maltose & $\begin{array}{l}\text { 2-Hydroxymethyl-2,5,7,8- } \\
\text { tetramethylchroman-6-ol } \\
\text { (vitamin E derivative) }\end{array}$ & $\begin{array}{l}\alpha \text {-Glucosidase from } \\
\text { Saccharomyces sp. }\end{array}$ & DMSO & $(20 \mathrm{~h})$ & 40 & $\begin{array}{c}\text { Murase } \\
\text { et al. } \\
1998\end{array}$ \\
\hline $\begin{array}{l}\beta \text {-D-Glucosyl-(1-6)-arbutin } \\
\beta \text {-D-Glucosyl-(1-4)-arbutin }\end{array}$ & Cellobiose & Arbutin & $\begin{array}{l}\beta \text {-Glucosidase from } \\
\text { Thermotoga }\end{array}$ & Buffer & $2.8 \%(12 \mathrm{~h})$ & 80 & $\begin{array}{l}\text { Jun et al. } \\
2008\end{array}$ \\
\hline$\beta$-D-Glucosyl-(1-3)-arbutin & & & neapolitana & & & & \\
\hline
\end{tabular}


2-hydroxymethyl-2,5,7,8-tetramethylchroman-6-ol (TM) and maltose using $\alpha$-glucosidase from Saccharomyces $\mathrm{sp}$. in a transglycosylation reaction (Murase et al. 1998). Antioxidant activity of TMG was investigated on peroxidation of phosphatidylcholine-liposomal (PC)-suspension, which is usually adopted as model for cellular biomembranes. TMG showed higher efficacy on lipid peroxidation than ascorbic acid, when peroxidation was provoked by lipid-soluble radical generator such as 2,2'-azobis(2,4-dimethylvaleronitrile (AMVN). Moreover, TMG showed to inhibit cupric ioninduced peroxidation of (PC)-suspension and rat brain homogenate while it delayed the generation of cholesteryl ester hydroperoxides when exposing human plasma to lipid or water-soluble radical generators.

A $\beta$-glucosidase from Thermotoga neapolitana has synthesized arbutin- $\beta$-glycosides to be used as novel skin whitening agents (Jun et al. 2008). $\beta$-D-glucosyl-(1-3)-arbutin has been proved to inhibit mushroom tyrosinase and it has been tested on B16F10 murine melanoma cell line showing the strongest inhibitory effect on melanin synthesis in a dosedependent manner without causing cytotoxicity. $\beta$-Dglucosyl-(1-3)-arbutin showed to be a more efficient inhibitor of melanin synthesis compared to arbutin. Similarly, arbutin has been glycosylated by a $\alpha$-glucosidase from Saccharomyces cerevisiae to produce 4-hydroxyphenyl- $\beta$ isomaltoside (Milosavić et al. 2007), whose inhibitory capacity on tyrosinase is being investigated. $\alpha$-Glucosidase from $S$. cerevisiae also catalyzed the synthesis of hydroquinone $\alpha$-D-glucopyranoside and hydroquinone $\alpha$-D-isomaltoside (Prodanović et al. 2005). Glycosylation of hydroquinone increased its water solubility and enhanced pharmaceutical properties such as skin whitening and anti-bacterial capacity.

\section{Laccases}

Laccases are dimeric or tetrameric glycosylated proteins, which usually bear four copper atoms per monomer distributed in three redox sites (Gianfreda et al. 1999). These enzymes are able to catalyze the one-electron oxidation of phenols generating phenoxy radicals and simultaneously reducing molecular dioxygen to water (Kudanga et al. 2011). Due to their features, including broad substrate specificity, catalysis in air without using $\mathrm{H}_{2} \mathrm{O}_{2}$, and production of water as only by-product, laccases are considered the ideal green catalysts. Besides catalyzing catabolic and depolymerization processes, based on reaction conditions, these enzymes can also carry out synthetic processes including the oxidization of aromatic compounds followed by heteromolecular coupling with cosubstrates or simple oligomerization (Mikolasch and Schauer 2009). The main compounds that have been synthesized by laccase-catalyzed reactions include flavonoids, HCAs, and other phenolics. Conditions of their production are described in the following sections and summarized in Table 7.

The anti-oxidant activity of flavonoids derives from the Bring, which is important for the H-transfer, and 2-3 double bond ensuring electron delocalization. Moreover, in vitro studies have demonstrated the importance of the 3-OH group for the anti-oxidant capacity. Rutin has been oxidized by a laccase from Myceliophtora thermophyla to produce flavonoid polymers (Kurisawa et al. 2003a). The same result was achieved by using Pycnoporus coccineus and Pycnoporus sanguineus laccases as biocatalysts. Oxidized poly-rutin showed enhanced anti-oxidant, anti-inflammatory, and antiaging capacities compared to the rutin monomer (Uzan et al. 2011). Enzymatic oxidation of catechin was also performed by a laccase from $M$. thermophyla producing poly-catechin with greater superoxide scavenging and inhibitory capacity of xanthine oxidase (Kurisawa et al. 2003b). Laccasecatalyzed oxidation has been applied in order to enhance the anti-oxidant property of FA. Two dimeric products, $\beta-5$ and $\beta-\beta$, were obtained by oxidation of FA in organic media using a laccase from Trametes pubescens (Adelakun et al. 2012b). Reaction was performed in a biphasic system, as the concentration of ethyl acetate increased, and in monophasic system using dioxane or ethanol as co-solvents. The $\beta-5$ dimer showed higher anti-oxidant capacity than FA evaluated by DPPH and Trolox equivalent antioxidant capacity (TEAC) assays. Different oxidized products of HCAs were used to improve anti-oxidant and anti-microbial activities of polymers, such as chitosan. A laccase from M. thermophyla was used to functionalize chitosan with oxidated FA and ethylferulate (Aljawish et al. 2012). Both derivatives showed higher anti-oxidant activity than the substrates, especially the FA chitosan. The same strategy was applied to functionalize chitosan with CA using a laccase from Trametes versicolor, obtaining a functionalized polymer with higher anti-oxidant and anti-microbial activity than the substrates (Božič et al. 2012b). These results indicated that the addition of an Hatom donating group, produced by laccase-mediated oxidization, could generate a good chain breaking anti-oxidant. Laccase-mediated oxidation is proved to be a good strategy to develop functionalized polymers with enhanced antioxidant and anti-microbial activities.

Oxidation of tannic acid by a laccase from $T$. versicolor resulted in a variety of products including gallic acid, gallic acid dimers, partially gallic acid-esterified glucose, and glucose, while oxidation of quercetin offered an oligomeric derivative (Božič et al. 2012a). Both oxidative products of gallic acid and quercetin showed higher anti-oxidant activity than the origin compounds. Furthermore, tannic acid or quercetin was used to functionalize chitosans by laccase without organic or acidic solvents. Both chitosan derivatives exhibited amplified radical scavenging ability and antimicrobial activity compared to the untreated chitosans. The 
Table 7 Laccase-catalyzed reactions

\begin{tabular}{|c|c|c|c|c|c|c|c|}
\hline Product & Donor & Acceptor & Enzyme & Solvent system & Yield (time) & $\begin{array}{l}\mathrm{T} \\
\left({ }^{\circ} \mathrm{C}\right)\end{array}$ & Reference \\
\hline Caffeic acid-chitosan & Caffeic acid & Chitosan & \multirow{5}{*}{$\begin{array}{l}\text { Laccase from Trametes } \\
\text { versicolor }\end{array}$} & \multirow{4}{*}{$\begin{array}{l}\text { Phosphate } \\
\text { buffer }\end{array}$} & $-(24 \mathrm{~h})$ & \multirow[t]{4}{*}{30} & Božič et al. \\
\hline Gallic acid-chitosan & Gallic acid & & & & $-(24 \mathrm{~h})$ & & 2012a \\
\hline Quercetin-chitosan & Quercetin & \multirow[t]{2}{*}{ Chitosan } & & & \multirow[t]{2}{*}{$-(24 h)$} & & Božič et al. \\
\hline Gallic acid-chitosan & Tannic acid & & & & & & $2012 b$ \\
\hline $\begin{array}{l}\text { Starch-sodium } \\
\text { lignosulfonate graft } \\
\text { copolymers }\end{array}$ & $\begin{array}{l}\text { Sodium } \\
\quad \text { lignosulfonate }\end{array}$ & Starch & & Sodium acetate & $-(4 \mathrm{~h})$ & 30 & $\begin{array}{l}\text { Shogren and } \\
\text { Biswas } \\
2013\end{array}$ \\
\hline $\begin{array}{l}\text { 3,3,5,5-Tetramethoxy } \\
\text { biphenyl-4,4-diol }\end{array}$ & $\begin{array}{l}\text { 2,6- } \\
\text { Dimethoxyphenol }\end{array}$ & $\begin{array}{l}\text { 2,6- } \\
\text { Dimethoxyphenol }\end{array}$ & \multirow[t]{3}{*}{$\begin{array}{l}\text { Laccase from Trametes } \\
\text { pubescens }\end{array}$} & $\begin{array}{l}\text { Ethyl acetate } \\
\text { Acetone }\end{array}$ & $\begin{array}{l}-(24 \mathrm{~h}) \\
-(24 \mathrm{~h})\end{array}$ & \multirow[t]{2}{*}{28} & $\begin{array}{l}\text { Adelakun } \\
\text { et al. } \\
\text { 2012a }\end{array}$ \\
\hline $\begin{array}{l}\text { Ferulic acid dimers }(5- \\
\qquad \beta, \beta-\beta)\end{array}$ & Ferulic acid & Ferulic acid & & $\begin{array}{l}\text { Ethyl acetate or } \\
\text { dioxane or } \\
\text { ethanol }\end{array}$ & $-(24 \mathrm{~h})$ & & $\begin{array}{l}\text { Adelakun } \\
\text { et al. } \\
2012 \mathrm{~b}\end{array}$ \\
\hline $\begin{array}{l}\text { Poly } 8 \text { - } \\
\text { hydroxyquinoline }\end{array}$ & 8- & 8- & & Acetone & $76 \%(24 h)$ & 30 & $\begin{array}{l}\text { Ncanana and } \\
\text { Burton } \\
2007\end{array}$ \\
\hline \multirow{2}{*}{$\begin{array}{l}\text { Resveratrol trans- } \\
\text { dehydrodimer }\end{array}$} & \multirow[t]{2}{*}{ Resveratrol } & \multirow[t]{2}{*}{ Resveratrol } & & Ethyl acetate & $18 \%$ (4 days) & \multirow{2}{*}{45} & \multirow{2}{*}{$\begin{array}{l}\text { Nicotra et al } \\
2004\end{array}$} \\
\hline & & & $\begin{array}{l}\text { Laccase from Myceliophtora } \\
\text { thermophyla (supported on } \\
\text { glass beads) }\end{array}$ & n-Butanol & $31 \%$ (4 days) & & \\
\hline $\begin{array}{l}\text { Ethyl-ferulate- } \\
\text { chitosan }\end{array}$ & Ethyl ferulate & Chitosan & $\begin{array}{l}\text { Laccase from Myceliophtora } \\
\text { thermophyla }\end{array}$ & $\begin{array}{l}\text { Phosphate } \\
\text { buffer }\end{array}$ & $(4 \mathrm{~h})$ & 30 & $\begin{array}{l}\text { Aljawish } \\
\quad \text { et al. } 2012\end{array}$ \\
\hline Ferulic acid-chitosan & Ferulic acid & & & & $(4 \mathrm{~h})$ & & \\
\hline Poly-catechin & $(+)$ - Catechin & $(+)$ - Catechin & & Acetone & $95 \%(24 \mathrm{~h})$ & RT & $\begin{array}{l}\text { Kurisawa } \\
\quad \text { et al. } \\
2003 \mathrm{~b}\end{array}$ \\
\hline Poly-rutin & Rutin & Rutin & & Methanol & $79 \%(24 \mathrm{~h})$ & RT & $\begin{array}{l}\text { Kurisawa } \\
\text { et al. } \\
\text { 2003a }\end{array}$ \\
\hline Oligorutin & Rutin & Rutin & $\begin{array}{l}\text { Laccase from Pycnoporus } \\
\text { coccineus } \\
\text { Laccase from Pycnoporus } \\
\text { sanguineus }\end{array}$ & $\begin{array}{l}\text { Glycerol/ } \\
\text { ethanol/ } \\
\text { buffer }\end{array}$ & $67 \%(24 \mathrm{~h})$ & RT & $\begin{array}{l}\text { Uzan et al. } \\
2011\end{array}$ \\
\hline
\end{tabular}

laccase grafting method was also applicable to other phenolic compounds, as in the case of graft copolymers of starch with lignosulfonates (Shogren and Biswas 2013). Enzymatic polymerization of 8-hydroxyquinoline was achieved by using a laccase from T. pubescens (Ncanana and Burton 2007). Oxidization of 8-hydroxyquinoline was established to generate aromatic radicals which combined to form a polymeric product with a powerful anti-oxidant capacity and anti-radical efficiency. Laccase-mediated oxidization was also performed in organic solvents, due to their advantages as medium in biocatalysis. Oxidation of 2,6-dimetho xyphenol by $T$. versicolor laccase was investigated in biphasic or monophasic systems, leading the formation of a dimeric product with anti-oxidant capacity twofold higher than the substrate. The dimer production was increased in the monophasic solvent using acetone as co-solvent, while its production increased as the concentration of ethyl acetate was increased to $90 \%$ in the biphasic system. Organic solvents were also applied in the synthesis of resveratrol dimers catalyzed by laccases from $M$. thermophyla and T. pubescens (Nicotra et al. 2004). M. thermophyla laccase-catalyzed dimers were obtained in butanol saturated with buffer; and resveratrol dimers catalyzed by T. pubescens laccase were synthesized using a biphasic system of ethyl acetate and buffer. The products may serve as lead for the development of new drugs and as nutraceuticals, showing anti-oxidant activity comparable to resveratrol and its analogs.

\section{Conclusions}

A large variety of compounds with potential cosmeceutical application can be obtained through biotechnological processes. The reported examples of enzymatic synthesis or modification of natural compounds so far exploited highlight the possibility of developing biologically active ingredients with anti-oxidant, anti-aging, anti-microbial, anti-wrinkling, photoprotective, or skin-whitening properties. The use of esterases (such as lipases, feruloyl esterases, tannases), transferases, glucosidases, proteases, and laccases allows the modification of target compounds under mild conditions, 
maintaining their biological activity and avoiding the formation of by-products. These advantages fit the increasing demand for natural cosmetics, boosting eco-friendly design and production of active compounds in order to replace chemical processes currently used.

Acknowledgments This work was supported by grant from European Union-Large-scale integrating project targeted to SMEs "Optimized esterase biocatalysts for cost-effective industrial production (OPTIBIOCAT)" grant agreement no. 613868, co-funded within the FP7 Knowledge Based Bio-Economy (KBBE).

\section{Compliance with ethical standards}

Funding This study was funded by grant from European Union Grant agreement no. 613868 .

Conflict of interest The authors declare that they have no conflict of interest.

Ethical approval This article does not contain any studies with human participants or animals performed by any of the authors.

Open Access This article is distributed under the terms of the Creative Commons Attribution 4.0 International License (http:// creativecommons.org/licenses/by/4.0/), which permits unrestricted use, distribution, and reproduction in any medium, provided you give appropriate credit to the original author(s) and the source, provide a link to the Creative Commons license, and indicate if changes were made.

\section{References}

Adelakun OE, Kudanga T, Green IR, le Roes-Hill M, Burton SG (2012a) Enzymatic modification of 2, 6-dimethoxyphenol for the synthesis of dimers with high antioxidant capacity. Process Biochem 47: 1926-1932. doi:10.1016/j.procbio.2012.06.027

Adelakun OE, Kudanga T, Parker A, Green IR, le Roes-Hill M, Burton SG (2012b) Laccase-catalyzed dimerization of ferulic acid amplifies antioxidant activity. J Mol Catal B Enzym 74:29-35. doi:10.1016/j. molcatb.2011.08.010

Aga H, Yoneyama SS, Yamamoto I (1991) Synthesis of 2-O- $\alpha$-dglucopyranosyl L-ascorbic acidby cyclomaltodextrin glucanotransferase from Bacillus stearothermophilus. Agric Biol Chem 55:1751-1756. doi:10.1080/00021369.1991.10870856

Aithal M, Belur PD (2013) Enhancement of propyl gallate yield in nonaquous medium using novel cell associated tannase of Bacillus massiliensis. Prep Biochem Biotechnol 43:445-455. doi:10.1080/ 10826068.2012.745873

Ajima A, Takahashi K, Matsushima A, Saito Y, Inada Y (1986) Retinyl esters synthesis by polyethylene glycol-modified lipase in benzene. Biotechnol Lett 8:547-552

Aljawish A, Chevalot I, Piffaut B, Rondeau-Mouro C, Girardin M, Jasniewski J, Schera J, Muniglia L (2012) Functionalization of chitosan by laccase-catalyzed oxidation of ferulic acid and ethyl ferulate under heterogeneous reaction conditions. Carbohydr Polym 87:537-544. doi:10.1016/j.carbpol.2011.08.016

Almeida VM, Branco CRC, Assis SA, Vieira IJC, Braz-Filho R, Branco A (2012) Synthesis of naringin 6"-ricinoleate using immobilized lipase. Chem Cent J 6:41. doi:10.1186/1752-153X-6-41
Andersen A, Bergfeld WF, Belsito DV, Hill RA, Klaassen CD, Liebler DC, Marks JG, Shank RC, Slaga TJ, Snyder PW (2010) Final amended safety assessment of hydroquinone as used in cosmetics. Int J Toxicol 29:2745-2875. doi:10.1177/1091581810385957

Zondlo Fiume M (2002) Final report on the safety assessment of tocopherol, tocopheryl acetate, tocopheryl linoleate, tocopheryl linoleate/ oleate, tocopheryl nicotinate, tocopheryl succinate, dioleyl tocopheryl methylsilanol, potassium ascorbyl tocopherol phosphate, and tocophersolan. Int J Toxicol 21:51-116

Aramsangtienchai P, Chavasiri W, Ito K, Pongsawasdi P (2011) Synthesis of epicatechin glucosides by a $\beta$-cyclodextrin glycosyltransfesrase. J Mol Catal B Enzym 73:27-34. doi:10.1016/j.molcatb.2011.07.013

Ardhaoui M, Falcimaigne A, Engasser JM, Moussou P, Pauly G, Ghoul M (2004b) Acylation of natural flavonoids using lipase of Candida antarctica as biocatalyst. J Mol Catal B Enzym 29:63-67. doi:10. 1016/j.molcatb.2004.02.013

Ardhaoui M, Falcimaigne A, Ognier S, Engasser JM, Moussou P, Pauly G, Ghoul M (2004a) Effect of acyl donor chain length and substitutions pattern on the enzymatic acylation of flavonoids. J Biotechnol 110:265-271. doi:10.1016/j.jbiotec.2004.03.003

Ashari SE, Mohamad R, Ariff A, Basir M, Salleh AB (2009) Optimization of enzymatic synthesis of palm-based kojic acid ester using response surface methodology. J Oleo Sci 58:503-510

Battestin V, Macedo GA, De Freitas VAP (2008) Hydrolysis of epigallocatechin gallate using a tannase from Paecilomyces variotii. Food Chem 108:228-233. doi:10.1016/j.foodchem.2007.10.068

Beena PS, Basheer SM, Bhat SG, Bahkali AH, Chandrasekaran M (2011) Propyl gallate synthesis using acidophilic tannase and simultaneous production of tannase and gallic acid by marine Aspergillus awamori BTMFW032. Appl Biochem Biotechnol 164:612-628. doi:10.1007/s12010-011-9162-x

Bouaziz A, Horchani H, Salem NB, Chaari A, Chaabouni M, Gargouri Y, Sayari A (2010) Enzymatic propyl gallate synthesis in solvent-free system: optimization by response surface methodology. J Mol Catal B Enzym 67:242-250. doi:10.1016/j.molcatb.2010.08.013

Bousquet MP, Willemot RM, Monsan P, Boures E (1999) Enzymatic synthesis of $\alpha$-butyl glycoside lactate: a new $\alpha$-hydroxy acid derivative. Biotechnol Bioeng 62:225-234

Božič M, Gorgieva S, Kokol V (2012a) Laccase-mediated functionalization of chitosan by caffeic and gallic acids for modulating antioxidant and antimicrobial properties. Carbohydr Polym 87:2388-2398. doi:10.1016/j.carbpol.2011.11.006

Božič M, Gorgieva S, Kokol V (2012b) Homogeneous and heterogeneous methods for laccase-mediated functionalization of chitosan by tannic acid and quercetin. Carbohydr Polym 89:854-864. doi: 10.1016/j.carbpol.2012.04.021

Bradoo S, Saxerna RK, Gupta R (1999) High yields of ascorbyl palmitate by thermostable lipase-mediated esterification. JAOCS 76:1291-1295

Brandt FS, Cazzaniga A, Hann M (2011) Cosmeceuticals: current trends and market analysis. Semin Cut Med Surg 1:141-143. doi:10.1016/ j.sder.2011.05.006

Burham H, Rasheed RAGA, Noor NM, Badruddin S, Sidek H (2009) Enzymatic synthesis of palm-based ascorbyl esters. J Mol Catal B Enzym 58:153-157. doi:10.1016/j.molcatb.2008.12.012

Cao X, Ito Y (2004) Preparation and purification of epigallocatechin by high-speed countercurrent chromatography (HSCC). J Liq Chromatogr Relat Technol 27:145-152. doi:10.1081/JLC120027091

Chandel C, Kumar A, Kanwar SS (2011) Enzymatic synthesis of butyl ferulate by silica-immobilized lipase in non-aqueous medium. J Biomed Nanotechnol 2:400-408. doi:10.4236/jbnb.2011.24049

Chebil L, Anthoni J, Humeau C, Gerardin C, Engasser JM, Ghoul M (2007) Enzymatic acylation of flavonoids: effect of the nature of the substrate, origin of lipase and operating conditions on conversion yield and regioselectivity. J Agric Food Chem 55:9496-9502. doi:10.1021/jf071943j 
Chen B, Liu H, Guo Z, Huang J, Wang M, Xu X, Zheng L (2011b) Lipase-catalyzed esterification of ferulic acid with oleyl alcohol in ionic liquid/isooctane binary systems. J Agric Food Chem 59:12561263. doi:10.1021/jf104101z

Chen CS, Liu KJ, Lou YH, Shieh CJ (2002) Optimization of kojic acid monolaurate synthesis with lipase PS from Pseudomonas cepacia. J Sci Food Agric 82:601-605. doi:10.1002/jsfa.1083

Chen HC, Chen JH, Chang C, Shieh CJ (2011a) Optimization of ultrasound-accelerated synthesis of enzymatic caffeic acid phenethyl ester by response surface methodology. Ultrason Sonochem 18: 455-459. doi:10.1016/j.ultsonch.2010.07.018

Chen HC, Twu YK, Chang CMJ, Liue YC, Shieh CJ (2010) Optimized synthesis of lipase-catalyzed octyl caffeate by Novozym ${ }^{\circledR} 435$. Ind Crop Prod 32:522-526. doi:10.1016/j.indcrop.2010.06.028

Chigorimbo-Murefu NTL, Riva S, Burton SG (2009) Lipase-catalysed synthesis of esters of ferulic acid with natural compounds and evaluation of their antioxidant properties. J Mol Cat: Enzym B 56:277282. doi:10.1016/j.molcatb.2008.05.017

Cho HK, Kim HH, Seo DH, Jung JH, Park JH, Baek NI, Kim MJ, Yoo SH, Cha J, Kim YR, Park CS (2011) Biosynthesis of (+)-catechin glycosides using recombinant amylosucrase from Deinococcus geothermalis DSM 11300. Enzym Microb Technol 49:246-253. doi:10.1016/j.enzmictec.2011.05.007

Choi CM, Berson DS (2006) Cosmeceuticals. Semin Cutan Med Surg 25: $163-168$

Ciftci D, Saldana MDA (2012) Enzymatic synthesis of phenolic lipids using flaxseed oil and ferulic acid in supercritical carbon dioxide media. J Supercrit Fluids 72:255-262. doi:10.1016/j.supflu.2012. 09.007

Compton DL, Laszlo (2009) 1,3-Diferuloyl-sn-glycerol from the biocatalytic transesterification of ethyl-4-hydroxy-3-methoxy cinnamic acid (ethyl ferulate) and soybean oil. Biotechnol Lett 31:889-896

Compton DL, Laszlo JA, Berhow MA (2000) Lipase-catalyzed synthesis of ferulate esters. JAOCS 77:513-519

Cosmetic Ingredient Review (1987) Final report on the safety assessment of retinyl palmitate and retinol. J Am Coll Toxicol 6:279-320. doi: $10.3109 / 10915818709098562$

Cosmetic International Review (2007) Final report on the amended safety assessment of propyl gallate. Int J Toxicol 26:89-118. doi:10.1080/ 10915810701663176

Costa ICR, Sutili FK, da Silva GVV, Leite SGF, Miranda LSM, de Souza ROMA (2014) Lipase catalyzed ascorbyl palmitate synthesis under microwave irradiation. J Mol Catal B Enzym 102:127-131. doi:10. 1016/j.molcatb.2014.02.002

Couto J, Karboune S, Mathew R (2010) Regioselective synthesis of feruloylated glycosides using the feruloyl esterase expressed in selected commercial multi-enzymatic preparations as biocatalysts. Biocatal Biotransfor 28:235-244. doi:10.3109/10242422.2010. 493209

Couto J, St-Louis R, Karboune S (2011) Optimization of feruloyl esterase-catalyzed synthesis of feruloylated oligosaccharides by response face methodology. J Mol Catal B Enzym 73:53-62. doi:10. 1016/j.molcatb.2011.07.016

Cui FJ, Zhao HX, Sun WJ, Wei Z, Yu SL, Zhou Q, Dong Y (2013) Ultrasound-assisted lipase-catalyzed synthesis of D-isoascorbyl palmitate: process optimization and kinetic evaluation. Chem Cent J 7: 180. doi:10.1186/1752-153X-7-180

Dal Belo SE, Gaspar LR, Maia Campos PMBG, Marty JP (2009) Skin penetration of epigallocatechin-3-gallate and quercetin from green tea and ginkgo biloba extracts vehiculated in cosmetic formulations. Skin Pharmacol Physiol 22:299-304. doi:10.1159/000241299

De Araujo MEMB, Contesini FJ, Franco YEM, Sawaya ACHF, Alberot TG, Dalfre N, Carvalho RO (2011) Optimized enzymatic synthesis of hesperidin fatty acid esters in a two-phase system containing ionic liquid. Molecules 16:7171-7182. doi:10.3390/molecules16087171
De Oliveira EB, Humeau C, Chebil L, Maia ER, Dehez F, Maigret B, Ghoul M, Engasser JM (2009) A molecular modeling study to rationalize the regioselectivity in acylation of flavonoid glycosides catalyzed by Candida antarctica lipase B. J Mol Catal B Enzym 59:96-105. doi:10.1016/j.molcatb.2009.01.011

Duan Y, Du Z, Yao Y, Li R, Wu D (2006) Effect of molecular sieves on lipase-catalyzed esterification of rutin with stearic acid. J Agric Food Chem 54:6219-6225

El-Boulifi N, Ashari SE, Serrano M, Aracil J, Martinez M (2014) Solvent-free lipase-catalyzed synthesis of a novel hydroxyl-fatty acid derivative of kojic acid. Enzym Microb Technol 55:128-132. doi:10.1016/j.enzmictec.2013.10.009

Enaud E, Humeau C, Piffaut B, Girardin M (2004) Enzymatic synthesis of new aromatic esters of phloridzin. J Mol Catal B Enzym 27:1-6. doi:10.1016/j.molcatb.2003.08.002

Fadnavis NW, Babu RL, Vadivel SK, Deshpande AA, Bhalerao UT (1998) Lipase catalyzed regio- and stereospecific hydrolysis: chemoenzymatic synthesis of both (R)- and (S)-enantiomers of alipoic acid. Tetrahedron Asymmetry 9:4109-4112. doi:10.1016/ S0957-4166(98)00447-9

Fernandez-Lorente G, Bolivar JM, Martin JR, Curiel JA, Munoz R, de las Rivas B, Carrascosa AV, Guisan JM (2011) Synthesis of propyl gallate by transesterification of tannic acid in aqueous media catalyzed by immobilized derivatives of tannase from Lactobacillus plantarum. Food Chem 128:214-217. doi:10.1016/j.foodchem. 2011.02.057

Form M, Adlercreutz P, Mattiasson B (1997) Lipase catalyzed esterification of lactic acid. Biotechnol Lett 19:315-317

Fornbacke M, Clarsund M (2013) Cold-adapted proteases as an emerging class of therapeutics. Infect Dis Ther 2:15-26. doi:10.1007/s40121013-0002-x

Funayama M, Nishino T, Hirota A, Murao S, Takenishi S, Nakano H (1993) Enzymatic synthesis of (+)catechin-a-glucoside and its effect on tyrosinase activity. Biosci Biotechnol Biochem 57:1666-1669. doi:10.1271/bbb.57.1666

Gazak R, Marhol P, Purchartova K, Monti D, Biedermann D, Riva S, Cvak L, Kren V (2010) Large-scale separation of silybin diastereoisomers using lipases. Process Biochem 45:1657-1663. doi:10. 1016/j.procbio.2010.06.019

Gianfreda L, Xu F, Bollag JM (1999) Laccases: a useful group of oxidoreductive enzymes. Biorem J 3:1-26. doi:10.1080/ 10889869991219163

Giuliani S, Piana C, Setti L, Hochkoeppler A, Pifferi PG, Williamson PG, Faulds CB (2001) Synthesis of pentylferulate by a feruloyl esterase from Aspergillus niger using water-in-oil microemulsions. Biotechnol Lett 23:325-330

Goncalves HB, Jorge JA, Pessela BC, Fernanzed Lorente G, Guisan JM, Guimaraes LHS (2013) Characterization of a tannase from Emericela nidulans immobilized on ionic and covalent supports for propyl gallate synthesis. Biotechnol Lett 35:591-598. doi:10. 1007/s10529-012-1111-4

Gulati R, Saxena RK, Gupta R, Yadav RP, Davidson S (1999) Parametric optimisation of Aspergillus terreus lipase production and its potential in ester synthesis. Process Biochem 35:459-464. doi:10.1016/ S0032-9592(99)00090-4

Ha SH, Van Anh T, Lee SH, Koo M (2012) Effect of ionic liquids on enzymatic synthesis of caffeic acid phenethyl ester. Bioprocess Biosyst Eng 35:235-240. doi:10.1007/s00449-011-0601-4

Hasegawa S, Azuma M, Takahashi K (2008) Enzymatic esterification of lactic acid, utilizing the basicity of particular polar organic solvents to suppress acidity of lactic acid. J Chem Technol Biotechnol 83: 1503-1510. doi:10.1002/jctb.1935

Hassan MA, Ismail F, Yamamoto S, Yamada H, Nakanishi K (1995) Enzymatic synthesis of galactosylkojic acid with immobilized bgalactosidase from Bacillus circulans. Biosci Biotechnol Biochem 59:543-545. doi:10.1271/bbb.59.543 
Hong YH, Jung EY, Shin KS, Kim TY, Yu KW, Chang UJ, Suh HJ (2012) Photoprotective effects of a formulation containing tannaseconverted green tea extract against UVB-induced oxidative stress in hairless mice. Appl Biochem Biotechnol 166:165-175. doi:10. 1007/s12010-011-9413-X

Hong YH, Jung EY, Shin KS, Yu KW, Chang UJ, Suh HJ (2013) Tannase-converted green tea catechins and their anti-wrinkle activity in humans. J Cosmet Dermatol 12:137-143. doi:10.1111/jocd. 12038

Hsieh HJ, Nair GR, Wu WT (2006) Production of ascorbyl palmitate by surfactant-coated lipase in organic media. J Agric Food Chem 54: $5777-5781$

Ishihara K, Nishimura Y, Kubo T, Okada C, Hamada H, Nakajima N (2002) Enzyme-catalyzed acylation of plant polyphenols for interpretation of their functions. Plant Biotechnology 19:211-214. doi: 10.5511/plantbiotechnology.19.211

Ishihara K, Katsube Y, Kumazawa N, Kuratani M, Masuoka N, Nakajima N (2010) Enzymatic preparation of arbutin derivatives: lipase-catalyzed direct acylation without the need of vinyl ester as an acyl donor. J Biosci Bioeng 109:554-556. doi:10.1016/j.jbiosc.2009.11.009

Jakovetic SM, Jugovic BZ, Gvozdenovic MM, Bezbradica DJI, Antov MG, Mijin DZ, Knezevic-Jugovic ZD (2013) Synthesis of aliphatic esters of cinnamic acid as potential lipophilic antioxidants catalyzed by lipase B from Candida antarctica. Appl Biochem Biotechnol 170:1560-1573. doi:10.1007/s12010-013-0294-Z

Jiang XJ, Hu Y, Jiang L, Gong JH, Huang H (2013) Synthesis of vitamin E succinate from Candida rugosa lipase in organic medium. Chem Res Chin Univ 29:223-226. doi:10.1007/s40242-013-2486-Z

Jun SY, Park KM, Choi KW, Jang MK, Kang HY, Lee SH, Park KH, Cha $J$ (2008) Inhibitory effects of arbutin- $\beta$-glycosides synthesized from enzymatic transglycosylation for melanogenesis. Biotechnol Lett 30:743-748. doi:10.1007/s10529-007-9605-1

Kaki SS, Grey C, Adlercreutz P (2012) Bioorganic synthesis, characterization and antioxidant activity of esters of natural phenolics and $\alpha$ lipoic acid. J Biotechnol 157:344-349. doi:10.1016/j.jbiotec.2011. 11.012

Kang J, Kim YM, Kim N, Kim DW, Nam SH, Kim D (2009) Synthesis and characterization of hydroquinone fructoside using Leuconostoc mesenteroides levansucrase. Appl Microbiol Biotechnol 83:10091016. doi:10.1007/s00253-009-1936-5

Katsoura MH, Polydera AC, Katapodis P, Kolisis FN, Stamatis H (2007) Effect of different reaction parameters on the lipase-catalyzed selective acylation of polyhydroxylated natural compounds in ionic liquids. Process Biochem 42:1326-1334. doi:10.1016/j.procbio.2007. 07.004

Katsoura MH, Polydera AC, Tsironis L, Tselepis AD, Stamatis H (2006) Use of ionic liquids as media for the biocatalytic preparation of flavonoid derivatives with antioxidant potency. J Biotechnol 123: 491-503. doi:10.1016/j.jbiotec.2005.12.022

Khamaruddin NH, Basri M, Lian GEC, Salleh AB, Abdul-Rahman RNZR, Ariff A, Mohamad R, Awang R (2008) Enzymatic synthesis and characterization of palm-based kojic acid ester. J Oil Palm Res 20:461-469

Khan NR, Rathod VK (2015) Enzyme catalyzed synthesis of cosmetic esters and its intensification: a review. Process Biochem 50:17931806. doi:10.1016/j.procbio.2015.07.014

Khmelnitsky YL, Hilhorst R, Veeger C (1988) Detergentless microemulsions as media for enzymatic reactions. Eur J Biochem $176: 265-271$

Kidwai M, Mothsra P, Gupta N, Jumar SS, Gupta R (2009) Green enzymatic synthesis of L-ascorbyl fatty acid ester: an antioxidant. Synth Commun 39:1143-1151. doi:10.1080/00397910802513045

Kikugawa M, Tsuchiyama M, Kai K, Sakamoto T (2012) Synthesis of highly water-soluble feruloyl diglycerols by esterification of an Aspergillus niger feruloyl esterase. Appl Microbiol Biotechnol 95: 615-622. doi:10.1007/s00253-012-4056-6
Kim GE, Kang HK, Seo ES, Jung SH, Park JS, Kim DH, Kim DW, Ahn SA, Sunwoo C, Kim D (2012) Glucosylation of the flavonoid, astragalin by Leuconostoc mesenteroides B-512FMCM dextransucrease acceptor reactions and characterization of the products. Enzym Microb Technol 50:50-56. doi:10.1016/j.enzmictec

Kim SK, Wijesekara I (2012) Chapter 1. Cosmeceuticals from marine resources: prospects and commercial trends. In: Kim S-K (ed) Marine cosmeceuticals - trends and prospects. CRC Press, Taylor \& Francis Group, New York ISBN 9781439860281

Kiran KR, Divakar S (2001) Lipase catalyzed synthesis of organic acid esters of lactic acid in non-aqueous media. J Biotechnol 87:109 121. doi:10.1016/S0168-1656(01)00242-5

Kitagawa M, Fan H, Raku T, Shibatani S, Maekawa Y, Hiraguri Y, et al. (1999) Selective enzymatic preparation of vinyl sugar esters using DMSO as a denaturing co-solvent. Biotechnol Lett 21:355-359. doi: 10.1023/A: 1005451009804

Kitao S, Matsudo T, Saitoh M, Horiuchi T, Sekine H (1995) Enzymatic syntheses of two stable (-)-epigallocatechin gallate-glucosides by sucrose phosphorylase. Biosci Biotechnol Biochem 59:21672169. doi:10.1271/bbb.59.2167

Kitao S, Sekine H (1994) a-D-glycosyl transfer of phenolic compounds by sucrose phosphorylase from Leuconostoc mesenteroides and production of a-arbutin. Biosci Biotechnol Biochem 58:38-42. doi:10. 1271/bbb. 58.38

Kitao S, Serine H (1994) Syntheses of two kojic acid glucosides with sucrose phosphorylase from Leuconostoc mesenteroides. Biosci Biotechnol Biochem 58:419-420. doi:10.1271/bbb.58.419

Kobayashi T, Adachi S, Nakanishi K, Matsuno R (2001) Semicontinuous production of lauroyl kojic acid through lipasecatalyzed condensation in acetonitrile. J Biochem Eng 9:85-89. doi:10.1016/S1369-703X(01)00129-2

Kudanga T, Nyanhongo GS, Guebitz GM, Burton S (2011) Potential applications of laccase-mediated coupling and grafting reactions: a review. Enzym Microb Technol 48:195-208. doi:10.1016/j. enzmictec.2010.11.007

Kurata A, Takemoto S, Fujita T, Iwai K, Furusawa M, Kishimoto N (2011) Synthesis of 3-cyclohexylpropyl caffeate from 5caffeoylquinic acid with consecutive enzymatic conversions in ionic liquid. J Mol Catal B Enzym 69:161-167. doi:10.1016/j.molcatb. 2011.01.012

Kurisawa M, Chung J, Uyama H, Kobayashi S (2003a) Laccasecatalyzed synthesis and antioxidant property of poly (catechin). Macromol Biosci 3:758-764. doi:10.1002/mabi.200300038

Kurisawa M, Chung JE, Uyama H, Kobayashi S (2003b) Enzymatic synthesis and antioxidant properties of poly (rutin). Biomacromoles 4:1394-1399. doi:10.1021/bm034136b

Kwon T, Kim CT, Lee JH (2007) Transglycosylation of ascorbic acid to ascorbic acid 2-glucoside by a recombinant sucrose phosphorylase feorm Bifidobacterium longum. Biotechnol Lett 29:611-615. doi: 10.1007/s10529-006-9285-2

Lajis AFB, Basir M, Mohamad R, Hamid M, Ashari SE, Ishak N, Zookiflie A, Ariff AB (2013) Enzymatic synthesis of kojic acid esters and their potential industrial applications. Chem Pap 67: 573-585. doi:10.2478/s11696-013-0336-6

Lajis AFB, Hamid M, Ariff AB (2012) Depigmenting effect of kojic acid esters in hyperpigmented B16F1 melanoma cells. J Biomed Biotechnol 2012:952452. doi:10.1155/2012/952452

Lambusta D, Nicolosi G, Patty A, Piattelli M (1993) Enzyme mediated regioprotection-deprotection of hydroxyl groups in $(+)$-catechin. Synthesis 11:1155-1158. doi:10.1055/s-1993-26019

Laszlo JA, Compton DL (2006) Enzymatic glycerolysis and transesterification of vegetable oil for enhanced production of feruloylated glycerols. JAOCS 83:765-770

Lee HJ, Kim JW (2012) Anti-inflammatory effects of arbutin in lipopolysaccharide-stimulated BV2 microglial cells. Inflamm Res 61:817-825. doi:10.1007/s00011-012-0474-02 
Li W, Wu H, Liu B, Hou X, Wan D, Lou W, Zhao J (2015) Highly efficient and regioselective synthesis of dihydromyricetinesters by immobilized lipase. J Biotechnol 199:31-37. doi:10.1016/j.jbiotec. 2015.02.012

Liu KJ, Shaw JF (1998) Lipase-catalyzed synthesis of kojic acid esters in organic solvents. JAOCS 75:1507-1511

Liu L, Pang M, Zhang Y (2015) Lipase-catalyzed regioselective synthesis of flavone C-glucosides esters and high-efficiency oil-soluble antioxidant of bamboo leaves. Eur J Lipid Sci Technol 117:1636-1646. doi:10.1002/ejlt.201400541

Liu ZQ, Zheng XB, Zhang SP, Zheng YG (2012) Cloning, expression and characterization of a lipase gene from the Candida antarctica ZJB09193 and its application in biosynthesis of vitamin A esters. Microbiol Res 167:452-460. doi:10.1016/j.micres.2011.12.004

Lue BM, Guo Z, Xu X (2010) Effect of room temperature ionic liquid structure on the enzymatic acylation of flavonoids. Process Biochem 45:1375-1382. doi:10.1016/j.procbio.2010.05.024

Luo XP, Du LH, He F, Zhou CH (2013) Controllable regioselective acylation of flavonoids catalyzed by lipase in microreactors. J Carbohydr Chem 32:450-462. doi:10.1080/07328303.2013. 843095

Lv LX, Chen SY, Li YQ (2008) Study of lipase-catalysed synthesis of ascorbyl benzoate in cyclohexanone using response surface methodology. J Sci Food Agric 88:659-666. doi:10.1002/jsfa.3132

Maczurek A, Hager K, Kenklies M, Sharman M, Martins R, Engel J, Carlson DA, Munch G (2008) Lipoic acid as an anti-inflammatory and neuroprotective treatment for Azheimer's disease. Adv Drug Deliv Rev 60:1463-1470. doi:10.1016/j.addr.2008.04.015

Mathew S, Adlercreutz P (2013) Regioselective glycosylation of hydroquinone to $\alpha$-arbutin by cyclodextrin glucanotransferase from Thermoanaerobacter sp. Biochem Eng J 79:187-193. doi:10. 1016/j.bej.2013.08.001

Matsuo T, Kobayashi T, Kimura Y, Hosoda A, Taniguchi H, Adachi S (2008) Continuous synthesis of glyceryl ferulate using immobilized Candida antarctica lipase. J Oleo Sci 57:375-380

Maugard T, Legoy MD (2000) Enzymatic synthesis of derivatives of vitamin A in organic media. J Mol Catal B Enzym 8:275-280. doi:10.1016/S1381-1177(99)00078-8

Mbatia B, Kaki SS, Mattiasson B, Mulla F, Adlercreutz P (2011) Enzymatic synthesis of lipophilic rutin and vanillyl esters from fish byproducts. J Agric Food Chem 59:7021-7027. doi:10.1021/ jf200867r

Mellou F, Lazari D, Skaltsa H, Tselepis AD, Kolisis FN, Stamatis H (2005) Biocatalytic preparation of acylated derivatives of flavonoid glycosides enhances their antioxidant and antimicrobial activity. J Biotechnol 116:295-304

Mellou F, Loutrari H, Stamatis H, Roussos C, Kolisis FN (2006) Enzymatic esterification of flavonoids with unsaturated fatty acids: effect of the novel esters on vascular endothelial growth factor release from K562 cells. Process Biochem 41:2029-2034. doi:10. 1016/j.procbio.2006.05.002

Mikolasch A, Schauer F (2009) Fungal laccases as tools for the synthesis of new hybrid molecules and biomaterials. Appl Microbiol Biotechnol 82:605-624. doi:10.1007/s00253-009-1869-z

Milisavljecic A, Stojanovic M, Carevic M, Mihailovic M, Velickoviz D, Milosavic N, Bezbradica D (2014) Lipase-catalyzed esterification of phloridzin: acyl donor effect on enzymatic affinity and antioxidant properties of esters. Ind Eng Chem Res 53(43):16644-16651. doi: 10.1021/ie5027259

Milosavić NB, Prodanović RM, Jankov RM (2007) A simple and efficient one-step, regioselective, enzymatic glucosylation of arbutin by $\alpha$-glucosidase. Tetrahedron Lett 48:7222-7224. doi:10.1016/j.tetlet. 2007.07.152

Moon YH, Lee JH, Ahn JS, Nam SH, Oh DK, Park DH, Chung HJ, Kang S, Day DF, Kim D (2006a) Synthesis, structure analyses and characterization of novel epigallocatechin gallate (EGCG) glycosides using a glucansucrase from Leuconostoc mesenteroides B-129CB. J Agric Food Chem 54:1230-1237. doi:10.1021/jf052359i

Moon YH, Lee JH, Jhon DY, Jun WJ, Kang SS, Sim J, Choi H, Moon JH, Kim D (2007b) Synthesis and characterization of novel quercetin-aD-glucopyranosides using glucansucrase from Leuconostoc mesenteroides. Enzym Microb Technol 40:1124-1129. doi:10. 1016/j.enzmictec.2006.08.019

Moon YM, Nam SH, Kang J, Kim YM, Lee JH, Kang HK, Breton V, Jun WJ, Park KD, Kimura A, Kim D (2007a) Enzymatic synthesis and characterization of arbutin glucosides using glucansucrase from Leuconostoc mesenteroides B-1299CB. Appl Microbiol Biotechnol 77:559-567. doi:10.1007/s00253-007-1202-7

Moreno-Perez S, Filice M, Guisan JM, Fernandez-Lorente G (2013) Synthesis of ascrobyl oleate by transesterification of olive oil wih ascorbic acid in polar organic media catalyzed by immobilized lipases. Chem Phys Lipids 174:48-54. doi:10.1016/j.chemphyslip. 2013.06.003

Murad S, Grove D, Lindberg KA, Reynolds G, Sivarajah A, Pinnell SR (1981) Regulation of collagen synthesis by ascorbic acid. Proc Natl Acad Sci U S A 78:2879-2882

Murase H, Moon JH, Yamauchi R, Kato K, Kunieda T, Yoshikawa T, Terao J (1998) Antioxidant activity of a novel vitamin E derivative, 2-( $\alpha$-L-glucopyranosyl) methyl-2, 5, 7, 8-tetramethylchroman-6-ol. Free Radic Biol Med 24:217-225. doi:10.1016/S0891-5849(97) 00221-9

Nagai M, Watanabe Y, Nomura M (2009) Synthesis of acyl arbutin by an immobilized lipase and its suppressive ability against lipid oxidation in a bulk system and $\mathrm{O} / \mathrm{W}$ emulsion. Biosci Biotechnol Biochem 73: 2501-2505

Nakahara K, Kontani M, Ono H, Kodama T, Tanaka T, Ooshima T, Hamada S (1995) Glycosyltransferase from Streptococcus sobrinus catalyzes glycosylation of catechin. Appl Environ Microbiol 61: $2768-2770$

Nazir N, Koul S, Qurishi MA, Taneja SC, Qazi GN (2009) Lipasecatalyzed regioselective protection/deprotection of hydroxyl groups of the isoflavone irilone isolated from Iris germanica. Biocatal Biotransfor 27:118-123. doi:10.1080/10242420802583457

Ncanana S, Burton S (2007) Oxidation of 8-hydroxyquinoline catalyzed by laccase from Trametes pubescens yields an antioxidant aromatic polymer. J Mol Catal B Enzym 44:66-71. doi:10.1016/j.molcatb. 2006.09.005

Nelson FP, Rumsfield J (1988) Cosmetics: content and function. Int J Dermatol 27:665-672

Nicotra S, Cramarossa MR, Mucci A, Pagnoni UM, Riva S, Forti L (2004) Biotransformation of resveratrol: synthesis of transdehydrodimers catalyzed by laccases from Myceliophtora thermophyla and from Trametes pubescens. Tetrahedron 60:595600. doi:10.1016/j.tet.2003.10.117

Nie G, Liu H, Chen Z, Wang P, Zhao G, Zheng Z (2012b) Synthesis of propyl gallate from tannic acid catalyzed by tannase from Aspergillus oryzae: process optimization of transesterification in anhydrous media. J Mol Catal B Enzym 82:102-108. doi:10.1016/j. molcatb.2012.06.003

Nie G, Zheng Z, Jin W, Gong G, Wang L (2012a) Development of a tannase biocatalyst based on bio-imprinting for the production of propyl gallate by transesterification in organic media. J Mol Catal B Enzym 78:32-37. doi:10.1016/j.molcatb.2012.01.007

Nie G, Zheng Z, Yue W, Liu Y, Liu H, Wang P, Zhao G, Cai W, Xue Z (2014) One-pot synthesis of propyl gallate by a novel whole-cell biocatalyst. Process Biochem 49:277-282. doi:10.1016/j.procbio. 2013.11.009

Nishimura T, Kometani T, Takii H, Terada Y, Okada S (1994) Acceptor specificity in the glycosylation reaction of Bacillus subtilis X-23 $\alpha$ amylase towards various phenolic compounds and the structure of kojic acid glucoside. J Ferment Bioeng 78:37-41 
Nohynek GI, Antignac E, Re T, Toutain H (2010) Safety assessment of personal care products/cosmetics and their ingredients. Toxicol Appl Pharmacol 243:239-259. doi:10.1016/j.taap.2009.12.001

Papadopoulou AA, Katsoura MH, Chatzikonstantinou A, Kyriakou E, Polydera A, Tzakos A, Stamatis H (2013) Enzymatic hybridization of $\alpha$-lipoic acid with bioactive compounds in ionic solvents. Bioresour Technol 136:41-48. doi:10.1016/j.biortech.2013.02.067

Park DW, Kim JS, Haam S, Kim HS, Kim WS (2001) Lipase-catalysed synthesis of $\beta$-methylglucoside esters containing an $\alpha$-hydroxy acid. Biotechnol Lett 23:1947-1952

Park S, Viklund F, Hult K, Kazlauskas RJ (2003) Vacuum-driven lipasecatalysed direct condensation of L-ascorbic acid and fatty acids in ionic liquids: synthesis of a natural surface active antioxidant. Green Chem 5:715-719. doi:10.1039/B307715B

Park TH, Choi KW, Park CS, Lee SB, Kang HY, Shon KJ, Park JS, Cha J (2005) Substrate specificity and transglycosylation catalyzed by a thermostable $\beta$-glucosidase from marine hyperthermophile Thermotoga neapolitana. Appl Microbiol Biotechnol 69:411-422. doi:10.1007/s00253-005-0055-1

Passicos E, Santarelli X, Coulon D (2004) Regioselective acylation of flavonoids catalyzed by immobilized Candida antarctica lipase under reduced pressure. Biotechnol Lett 26:1073-1076

Pedersen NR, Halling PJ, Pedersen LH, Wimmer R, Matthiesen R, Veltman OR (2002) Efficient transesterification of sucrose catalysed by the metalloprotease thermolysin in dimethylsulfoxide. FEBS Lett 519:181-184. doi:10.1016/S0014-5793(02)02753-9

Pedersen NR, Wimmer R, Matthiesen R, Pedersen LH, Gessesse A (2003) Synthesis of sucrose laurate using a new alkaline protease. Tetrahedron Asymmetry 14:667-673. doi:10.1016/S0957-4166(03) 00086-7

Pirozzi D, Greco G Jr (2004) Activity and stability of lipases in the synthesis of butyl lactate. Enzym Microb Technol 34:94-100. doi: 10.1016/j.enzmictec.2003.01.002

Pleiss J, Fischer M, Schmid R (1998) Anatomy of lipase binding sites: the scissile fatty acid binding site. Chem Phys Lipids 93:67-80. doi:10. 1016/S0009-3084(98)00030-9

Prasad D, Grupt RK, Venkataratnam GS, Kamin NR, Gowthaman MK (2011) Utilization of bahera fruits for production of tannase and gallic acid by Aspergillus heteromorphus MTCC 5466 and synthesis of propyl gallate thereof. Global J Biotech Biochem 6:119-128

Prodanović R, Milosavić N, Sladić D, Zlatović M, Božić B, Veličković TĆ, Vujčić Z (2005) Transglucosylation of hydroquinone catalysed by $\alpha$-glucosidase from baker's yeast. J Mol Catal B Enzym 35:142146. doi:10.1016/j.molcatb.2005.06.011

Raab T, Bel-Rhid R, Williamson G, Hansen CE, Chaillot D (2007) Enzymatic galloylation of catechins in room temperature ionic liquids. J Mol Catal B Enzym 44:60-65. doi:10.1016/j.molcatb.2006. 09.003

Radzi SM, Rahman NJA, Noor HM, Ariffin N (2014) Enzymatic synthesis of olive-based ferulate esters: optimization by response surface methodology. IJISR 8:762-765

Raku T, Tokiwa Y (2003) Regioselective synthesis of kojic acid esters by Bacillus subtilis protease. Biotechnol Lett 25:969-974. doi:10.1023/ A:1024088303960

Rejasse B, Maugard T, Legoy MD (2003) Enzymatic procedures for the synthesis of water-soluble retinol derivatives in organic media. Enzym Microb Technol 32:312-320. doi:10.1016/S0141-0229(02) 00289-2

Reyes-Duarte D, Lopez-Cortes N, Torres P, Comelles F, Parra JL, Pena S, Ugidos AV, Ballesteros A, Plou FJ (2011) Synthesis and properties of ascorbyl esters catalyzed by lipozyme TL IM using triglycerides as acyl donors. J Am Oil Chem Soc 88:57-64. doi:10.1007/s11746010-1643-5

Riva S (1996) A two-step efficient chemoenzymatic synthesis of flavonoid glycoside malonates. J Nat Prod 59:618-621. doi:10.1021/ np960239m
Roenne TH, Xu X, Tan T (2005) Lipase-catalyzed esterification of lactic acid with straight-chain alcohols. JAOCS 82:881-885

Sabally K, Karboune S, St-Louis R, Kermasha S (2006) Lipase-catalyzed transesterification of trilinolein or trilinolenin with selected phenolic acids. JAOCS 83:101-107

Salas MP, Celiz G, Geronazzo H, Daz M, Resnik SL (2011) Antifungal activity of natural and enzymatically-modified flavonoids isolated from citrus species. Food Chem 124:1411-1415. doi:10.1016/j. foodchem.2010.07.100

Salem JH, Humeau C, Chevalot I, Harscoat-Schiavo C, Vanderesse R, Blanchard F, Fick F (2010) Effect of acyl donor chain length on isoquercitrin acylation and biological activities of corresponding esters. Process Biochem 45:382-389. doi:10.1016/j.procbio.2009. 10.012

Sato T, Nakagawa H, Kurosu J, Yoshida K, Tsugane T, Shimura S, Kirimura K, Kino K, Usami S (2000) Alpha-anomer-selective glucosylation of $(+)$-catechin by the crude enzyme, showing glucosyl transfer activity, of Xanthomonas campestris WU-9701. J Biosci Bioeng 90:625-630

Seo DH, Jung JH, Ha SJ, Cho HK, Jung DH, Kim TJ, Baek NI, Yoo SH, Part CS (2012b) High-yield enzymatic bioconversion of hydroquinone to $\alpha$-arbutin, a powerful skin lightening agent, by amylosucrase. Appl Microbiol Biotechnol 94:1189-1197. doi:10. 1007/s00253-012-3905-7

Seo DH, Jung JH, Lee JE, Jeon EJ, Kim W, Park CS (2012a) Biotechnological production of arbutins ( $\alpha$ - and $\beta$-arbutins), skinlightening agents, and their derivatives. Appl Microbiol Biotechnol 95:1417-1425. doi:10.1007/s00253-012-4297-4

Seo ES, Kang J, Lee JH, Kim GE, Kim GJ, Kim D (2009) Synthesis and characterization of hydroquinone glucoside using Leuconostoc mesenteroides dextransucrase. Enzym Microb Technol 45:355360. doi:10.1016/j.enzmictec.2009.07.011

Sharma P (2011) Cosmeceuticals: regulatory scenario in the US, Europe and India. Int J Pharm Technol 3:1512-1535

Sharma S, Gupta MN (2003) Synthesis of antioxidant propyl gallate using tannase from Aspergillus niger van Teighem in nonaqueous media. Bioorg Med Chem Lett 13:395-397. doi:10.1016/S0960894X(02)00977-0

Sharma S, Saxena RK (2012) Evaluation of the versatility of the tannases produced from Aspergillus niger and Penicillium variable with respect to gallic acid production, gallate ester synthesis, animal feed improvement, tannery effluent degradation and tannin stain removal. Res Biotechnol 3:9-20

Shin MH, Cheong NY, Lee JH, Kim KH (2009) Transglucosylation of caffeic acid by a recombinant sucrose phosphorylase in aqueous buffer and aqueous-supercritical CO2 media. Food Chem 115: 1028-1033. doi:10.1016/j.foodchem.2009.01.013

Shogren RL, Biswas A (2013) Preparation of starch-sodium lignosulfonate graft copolymers via laccase catalysis and characterization of antioxidant activity. Carbohydr Polym 91:581-585. doi:10.1016/j. carbpol.2012.08.079

Stevenson DE, Wibisono R, Jensen DJ, Stanley RA, Cooney JM (2006) Direct acylation of flavonoid glycosides with phenolic acids catalysed by Candida antarctica lipase B (Novozym $435^{\circledR}$ ). Enzym Microb Technol 39:1236-1241. doi:10.1016/j.enzmictec. 2006.03.006

Sugimoto K, Nishimura T, Nomura K, Sugimoto K, Kuriki T (2003) Synthesis of arbutin $\alpha$-glucosides and a comparison of their inhibitory effects with those of $\alpha$-arbutin and arbutin on human tyrosinase. Chem Pharm Bull 51:798-801

Sugimoto K, Nomura J, Nishimura T, Kiso T, Sugimoto K, Kuriki T (2005) Synthesis of $\alpha$-arbutin- $\alpha$-glycosides and their inhibitory effects on human tyrosinase. J Biosci Bioeng 99:272-276

Sugimoto K, Nomura K, Nishiura H, Ohdan K, Nishimura T, Hayashi H, Kuriki T (2007) Novel transglucosylating reaction of sucrose 
phosphorylase to carboxylic compounds such as benzoic acid. J Biosci Bioeng 104:22-29. doi:10.1263/jbb.104.22

Sun S, Qin F, Bi Y, Chen J, Yang G, Liu W (2013b) Enhanced transesterification of ethyl ferulate with glycerolfor preparing glyceryl diferulate using a lipase in ionic liquids as reaction medium. Biotechnol Lett 35:1449-1454. doi:10.1007/s10529-013-1222-6

Sun S, Shan L, Liu Y, Jin Q, Wang X, Wang Z (2007) A novel, two consecutive enzyme synthesis of feruloylated monoacyl- and diacyl-glycerols in a solvent-free system. Biotechnol Lett 29: 1947-1950. doi:10.1007/s10529-007-9486-3

Sun S, Shan L, Liu Y, Jin Y, Jin Q, Song Y, Wang X (2009) Solvent-free enzymatic synthesis of feruloylated diacylglycerols and kinetic study. J Mol Catal B Enzym 57:104-108. doi:10.1016/j.molcatb. 2008.07.010

Sun S, Song F, Bi Y, Yang G, Liu W (2013a) Solvent-free enzymatic transesterification of ethyl ferulate and monostearin: optimized by response surface methodology. J Biotechnol 164:340-345. doi:10. 1016/j.jbiotec.2013.01.013

Sun S, Zhu S, Bi Y (2014) Solvent-free enzymatic synthesis of feruloylated structured lipids by the transesterification of ethyl ferulate with castor oil. Food Chemistry 158:292-295. doi:10. 1016/j.foodchem.2014.02.146

Takami M, Hidaka N, Miki S, Suzuki Y (1994) Enzymatic synthesis of novel phosphatidylkojic acid and phosphatidylarbutin, and their inhibitory effects on tyrosinase activity. Biosci Biotechnol Biochem 58:1716-1717. doi:10.1271/bbb.58.1716

Tan Z, Shahidi F (2011) Chemoenzymatic synthesis of phytosteryl ferulates and evaluation of their antioxidant activity. J Agric Food Chem 59:12375-12383. doi:10.1021/jf2034237

Tan Z, Shahidi F (2012) A novel chemoenzymatic synthesis of phytosteryl caffeates and assessment of their antioxidant activity. Food Chem 133:1427-1434. doi:10.1016/j.foodchem.2012.02.030

Tan Z, Shahidi F (2013) Phytosteryl sinapates and vanillates: chemoenzymatic synthesis and antioxidant capacity assessment. Food Chem 138:1438-1447. doi:10.1016/j.foodchem.2012.10.093

Theodosiou E, Katsoura MH, Loutrari H, Purchartova K, Kren V, Kolisis FN, Stamatis H (2009) Enzymatic preparation of acylated derivatives of silybin in organic and ionic liquid media and evaluation of their antitumour proliferative activity. Biocatal Biotransfor 27:161169. doi:10.1080/10242420902937777

Tokiwa Y, Kitagawa M, Raku T (2007a) Enzymatic synthesis of arbutin undecylenic acid ester and its inhibitory effect on mushroom tyrosinase. Biotechnol Lett 29:481-486. doi:10.1007/s10529-006-9267-4

Tokiwa Y, Kitagawa M, Raku T, Yanagitani S, Yoshino K (2007b) Enzymatic synthesis of arbutin undecylenic acid ester and its inhibitory effect on melanin synthesis. Bioorg Med Chem Lett 17:31053108. doi:10.1016/j.bmcl.2007.03.039

Topakas E, Stamatis H, Biely P, Kekos D, Macris BJ, Christakopoulos P (2003b) Purification and characterization of a feruloyl esterase from Fusarium oxysporum catalyzing esterification of phenolic acids in ternary water-organic solvent mixtures. J Biotechnol 102:33-44. doi:10.1016/S0168-1656(02)00363-2

Topakas E, Stamatis H, Biely P, Christakopoulos P (2004) Purification and characterization of a type B feruloyl esterase (StFae-A) from the thermophilic fungus Sporotrichum thermophile. Appl Microbiol Biotechnol 63:686-690

Topakas E, Stamatis H, Mastihubova M, Biely P, Kekos D, Macris BJ, Christakopoulos P (2003a) Purification and characterization of a Fusarium oxysporum feruloyl esterase (FoFAE-I) catalysing transesterification of phenolic acid esters. Enzym Microb Technol 33:729-737. doi:10.1016/S0141-0229(03)00213-8

Torres C, Otero C (1999) Part I: enzymatic synthesis of lactate and glycolate esters of fatty alcohols. Enzym Microb Technol 25:745752. doi:10.1016/S0141-0229(99)00117-9
Torres C, Otero C (2001) Part III: direct enzymatic esterification of lactic acid with fatty acids. Enzym Microb Technol 29:3-12. doi:10.1016/ S0141-0229(01)00344-1

Torres P, Kunamneni A, Ballesteros A, Plou FJ (2008a) Enzymatic modification of ascorbic acid and alpha-tocopherol to enhance their stability in food and nutritional applications. Open Food Sci J 2:1-9

Torres P, Reyes-Duarte D, Lopez-Cortes N, Ferrer M, Ballesteros A, Plou FJ (2008b) Acetylation of vitamin E by Candida antarctica lipase B immobilized on different carries. Process Biochem 43:145-153. doi: 10.1016/j.procbio.2007.11.008

Toth G, Hensler D (1952) The enzymatic synthesis of gallic acid derivatives. Acta Chim II 10:209-212

Tsuchiyama M, Sakamoto T, Fujita T, Murata S, Kawasaki H (2006) Esterification of ferulic acid with polyols using a ferulic acid esterase from Aspergillus niger. Biochim Biophys Acta 7:1071-1079. doi: 10.1016/j.bbagen.2006.03.022

Tsuchiyama M, Sakamoto T, Tanimori S, Murata S, Kawasaki H (2007) Enzymatic synthesis of hydroxycinnamic acid glycerol esters using type A feruloyl esterase from Aspergillus niger. Biosci Biotechnol Biochem 71:2606-2609

Tung RC, Bergfeld WF, Vidimos AT, Remzi BK (2000) $\alpha$-Hydroxy acidbased cosmetic procedures. Am J Chin Dermatol 1:81-88

Uzan E, Portet B, Lubrano C, Milesi S, Favel A, Lesage-Meessen L, Lomascolo A (2011) Pycnoporus laccase-mediated bioconversion of rutin to oligomers suitable for biotechnology applications. Appl Microbiol Biotechnol 90:97-105. doi:10.1007/s00253-010-3075-4

Vafiadi C, Topakas E, Alderwick LJ, Besra GS, Christakopoulos P (2007a) Chemoenzymatic synthesis of feruloyl-D-arabinose as a potential anti-mycobacterial agent. Biotechnol Lett 29:1771-1774

Vafiadi C, Topakas E, Alissandratos A, Faulds CB, Christakopoulos P (2008b) Enzymatic synthesis of butyl hydroxycinnamates and their inhibitory effect on LDL-oxidation. J Biotechnol 133:497-504

Vafiadi C, Topakas E, Bakx EJ, Schols HA, Christakopoulos P (2007b) Structural characterization of ESI-MS of feruloylated arabinooligosaccharides synthesized by chemoenzymatic esterification. Molecules 12:1367-1375

Vafiadi C, Topakas E, Christakopoulos P (2008a) Preparation of multipurpose cross-linked enzyme aggregates and their application to production of alkyl ferulates. J Mol Catal B Enzym 54:35-41. doi: 10.1016/j.molcatb.2007.12.005

Vafiadi C, Topakas E, Christakopoulos P, Faulds CB (2006) The feruloyl esterase system of Talaromyces stipitatus: determining the hydrolytic and synthetic specificity of TsFaeC. J Biotechnol 125:210-221

Vafiadi C, Topakas E, Wong KKY, Suckling ID, Christakopoulos P (2005) Mapping the hydrolytic and synthetic selectivity of a type $\mathrm{C}$ feruloyl esterase (StFaeC) from Sporotrichum thermophile using alkyl ferulates. Tetrahedron Asymmetry 16:373-379. doi:10.1016/j. tetasy.2004.11.037

Vafiadi C, Topakas E, Nahmias VR, Faulds CB, Christakopoulos P (2009) Feruloyl esterase-catalyzed synthesis of glycerol sinapate using ionic liquid mixtures. J Biotechnol 139:124-129. doi:10. 1016/j.jbiotec.2008.08.008

Vavrikova E, Vacek J, Valentova K, Marchol P, Ulrichova J, Kuzma M, Kren V (2014) Chemo-enzymatic synthesis of silybin and 2,3dehydrosilybin dimers. Molecules 19:4115-4134. doi:10.3390/ molecules 19044115

Viklund F, Alander J, Hult K (2003) Antioxidative properties and enzymatic synthesis of ascorbyl FA esters. JAOCS 80:795-799

Viskupicova J, Danihelova M, Ondrejovic M, Liptaj T, Sturdik E (2010) Lipophilic rutin derivatives for antioxidant protection of oil-based foods. Food Chem 123:45-50. doi:10.1016/j.foodchem.2010.03.125

Wang J, Gu SS, Cui HS, Wu XY, Wu FA (2014) A novel continuous flow biosynthesis of caffeic acid phenethyl ester from alkyl caffeate and phenethanol in a packed bed microreactor. Bioresour Technol 158: 39-47. doi:10.1016/j.biortech.2014.01.145 
Wang J, Gu SS, Cui HS, Yang LQ, Wu XY (2013) Rapid synthesis of propyl caffeate in ionic liquid using a packed bed enzyme microreactor under continuous-flow conditions. Bioresour Technol 149:367-374. doi:10.1016/j.biortech.2013.09.098

Wang J, Wang S, Li Z, Gu S, Wu X, Wu F (2015) Ultrasound irradiation accelerates the lipase-catalyzed synthesis of methyl caffeate in an ionic liquid. J Mol Catal B Enzym 111:21-28. doi:10.1016/j. molcatb.2014.11.006

Watanabe Y, Kuwabara K, Adachi S, Nakanishi K, Matsuno R (2003) Production of saturated acyl-L-ascorbate by immobilized lipase using a continuous stirred tank reactor. J Agric Food Chem 51: $4628-4632$

Watanabe Y, Nagai M, Yamanaka K, Jose K, Nomura M (2009) Synthesis of lauroyl phenolic glycoside by immobilized lipase in organic solvent and its antioxidative activity. J Biochem Eng 43:261-265. doi: 10.1016/j.bej.2008.10.008

Watanabe Y, Sawahara Y, Nosaka H, Yamanaka K, Adachi S (2008) Enzymatic synthesis of conjugated linoleoyl ascorbate in acetone. Biochem Eng J 40:268-372. doi:10.1016/j.bej.2008.01.007

Weetall HH (1985) Enzymatic synthesis of gallic acid esters. Appl Biochem Biotechnol 11

Wei D, Gu C, Song Q, Su W (2003) Enzymatic esterification for glycoside lactate synthesis in organic solvent. Enzym Microb Technol 33: 508-512. doi:10.1016/S0141-0229(03)00156-X

Wei DZ, Zou P, Tu MB, Zheng H (2002) Enzymatic synthesis of ethyl glucoside lactate in non-aqueous system. J Mol Catal B Enzym 18: 273-278. doi:10.1016/S1381-1177(02)00106-6

Widjaja A, Yeh TH, Ju YH (2008) Enzymatic synthesis of caffeic acid phenethyl ester. J Chin Inst Chem Eng 39:413-418. doi:10.1016/j. jcice.2008.05.003

Woo HJ, Kang HK, Nguyen TTH, Kim GE, Kim YM, Park JS, Kim D, Cha J, Moon YH, Nam SH, Xia YM, Kimura A, Kim D (2012) Synthesis and characterization of ampelopsin glucosides using dextransucrase from Leuconostoc mesenteroides B-1299CB4: glucosylation enhancing physicochemical properties. Enzym Microb Technol 51:311-318. doi:10.1016/j.enzmictec.2012.07.014

Xiao Y, Yang L, Mao P, Zhao Z, Lin X (2011) Ultrasound-promoted enzymatic synthesis of troxerutin esters in nonaqueous solvents. Ultrason Sonochem 18:303-309. doi:10.1016/j.ultsonch.2010.06.010

Xiao YM, Wu Q, Wu WB, Zhang QY, Lin XF (2005) Controllable regioselective acylation of rutin catalyzed by enzymes in non-aqueous solvents. Biotechnol Lett 27:1591-1595. doi:10.1007/s10529-0052513-3

Xin JY, Chen LI, Zhang YX, Wen RR, Zhao DM, Xia CG (2011) Lipasecatalyzed synthesis of a-tocopheryl ferulate. Food Biotechnol 25: 43-57. doi:10.1080/08905436.2011.547116

Xin JY, Zhang L, Chem LL, Zheng Y, Wu XM, Xia CG (2009) Lipasecatalyzed synthesis of feruloyl oleins in solvent-free medium. Food Chem 112:640-645. doi:10.1016/j.foodchem.2008.06.024

Yan H, Wang Z, Chen L (2009) Kinetic resolution of $\alpha$-lipoic acid via enzymatic differentiation of a remote stereocenter. J Ind Microbiol Biotechnol 36:643-648. doi:10.1007/s10295-009-0531-1

Yang H, Mu Y, Chen H, Xiu Z, Yang T (2013) Enzymatic synthesis of feruloylated lysophospholipid in a selected organic solvent medium. Food Chem 141:3317-3322. doi:10.1016/j.foodchem.2013.06.012

Yang HD, Wang Z, Chen LJ (2009) Kinetic resolution of a-lipoic acid via enzymatic differentiation of a remote sterocenter. J Ind Microbiol Biotechnol 36:643-648. doi:10.1007/s10295-009-0531-1

Yang RL, Li N, Li RF, Smith TJ, Zong MH (2010a) A highly regioselective route to arbutin esters by immobilized lipase from Penicillium expansum. Bioresour Technol 101:1-5. doi:10.1016/j.biortech. 2009.07.067

Yang RL, Li N, Ye M, Zong MH (2010b) Highly regioselective synthesis of novel aromatic esters of arbutin catalyzed by immobilized lipase from Penicillium expansum. J Mol Catal B Enzym 67:41-44. doi: 10.1016/j.molcatb.2010.07.003

Yang Z, Glasius M, Xu X (2012) Enzymatic transesterification of ethyl ferulate with fish oil and reaction optimization by response surface methodology. Food Technol Biotechnol 50:88-97

Yin C, Liu T, Tan T (2006) Synthesis of vitamin A esters by immobilized Candida sp. lipase in organic media. Chin J Chem Eng 14:81-86. doi:10.1016/S1004-9541(06)60041-4

Yin C, Zhang C, Gao M (2011) Enzyme-catalyzed synthesis of vitamin E succinate using a chemically modified Novozym- 435 . Chin J Chem Eng 19:135-139. doi:10.1016/S1004-9541(09)60189-0

Yu XW, Li YQ (2005) Microencapsulated mycelium-bound tannase from Aspergillus niger an efficient catalyst for esterification of propyl gallate in organic solvents. Appl Biochem Biotechnol 126:177-187

Yu XW, Li YQ (2008) Expression of Aspergillus oryzae tannase in Pichia pastoris and its application in the synthesis of propyl gallate in organic solvent. Food Technol Biotechnol 46:80-85

Yu XW, Li YQ, Zhou SH, Zheng YY (2007) Synthesis of propyl gallate by mycelium-bound tannase from Aspergillus niger in organic solvent. World J Microbiol Biotechnol 23:1091-1098. doi:10.1007/ s11274-006-9338-7

Yu Y, Zheng Y, Quan J, Wu CY, Wang YJ, Brandford-White C, Zhu LM (2010) Enzymatic synthesis of feruloylated lipids: comparison of the efficiency of vinyl ferulate and ethyl ferulate as substrates. J Am Oil Chem Soc J 87:1443-1449. doi:10.1007/s11746-010-1636-4

Zeuner B, Ståhlberg T, van Buu ON, Kunov-Kruse AJ, Riisager A, Meyer AS (2011) Dependency of the hydrogen bonding capacity of the solvent anion on the thermal stability of feruloyl esterases in ionic liquid systems. Green Chem 13:1550-1557. doi:10.1039/ C1GC15115K

Zhang DH, Li YQ, Li C, Lv YQ, Yv-Qin L, Yang L (2012) Kinetics of enzymatic synthesis of L-ascorbyl acetate by lipozyme TLIM and Novozym 435. Biotechnol Bioprocess Eng 17:60-66. doi:10.1007/ s12257-011-0249-6

Zhang S (2015) Novel trends for use of microbial tannases. Prep Biochem Biotechnol 45:221-232. doi:10.1080/10826068.2014.907182

Zhao H, Liu J, Lv F, Ye R, Bie X, Zhang C, Lu Z (2014) Enzymatic synthesis of lard-based ascorbyl esters in a packed-bed reactor: optimization by response surface methodology and evaluation of antioxidant properties. LWT Food Sci Technol 57:393-399. doi:10. 1016/j.lwt.2013.12.015

Zheng MM, Wang L, Huang FH, Guo PM, Wei F, Deng QC, Zheng C, Wan CY (2013) Ultrasound irradiation promoted lipase-catalyzed synthesis of flavonoid esters with unsaturated fatty acids. J Mol Catal B Enzym 95:82-88. doi:10.1016/j.molcatb.2013.05.028

Zheng Y, Quan J, Zhu LM, Jiang B, Nie HL (2008) Optimization of selective lipase-catalyzed feruloylated monoacylglycerols by response surface methodology. J Am Oil Chem Soc 85:635-639. doi:10.1007/s11746-008-1248-4

Zhu S, Li Y, Li Z, Ma C, Lou Z, Yokoyama W, Wang H (2014) Lipasecatalyzed synthesis of acetylated EGCG and antioxidant properties of the acetylated derivatives. Food Res Int 56:279-286. doi:10. 1016/j.foodres.2013.10.026

Ziaullah HPVR (2013) An efficient microwave-assisted enzyme-catalyzed regioselective synthesis of long chain acylated derivatives of flavonoid glycosides. Tetrahedron Lett 54:1933-1937. doi:10.1016/ j.tetlet.2013.01.103 